\title{
HACIA UNA EDICIÓN CRÍTICA DEL EXAMEN DEL ANTÍDOTO DE FRANCISCO FERNÁNDEZ DE CÓRDOBA ${ }^{1}$
}

\author{
Matteo Mancinelli \\ Università di Ferrara - Universidad de Córdoba \\ mncmtt@unife.it
}

\begin{abstract}
$\mathrm{C}$
omúnmente conocido bajo el título de Examen del Antídoto, el Examen del Antídoto o Apología por las Soledades de don Luis de Góngora contra el autor del Antídoto de Francisco Fernández de Córdoba, abad de Rute, es sin duda una de las defensas más eruditas de las Soledades gongorinas. Escrito entre finales de 1616 y principios de 1617 -según se infiere de algunas cartas del mismo autor ${ }^{2}-$, representa la respuesta más profunda al Antídoto (1614-1615) de Juan de Jáuregui ${ }^{3}$. Su primera y única publicación, que data de 1925 , se debe a Miguel Artigas ${ }^{4}$, el cual transcribió diplomáticamente uno de los testimonios en los que se conserva la obra (el ms. 3803 de la Biblioteca Nacional de España). Desde entonces, el tratado del abad de Rute no ha conocido otra edición, aun cuando otras voces venían clamando -acaso en el desierto- porque abandonara el sueño de los justos ${ }^{5}$.
\end{abstract}

1 Este trabajo ha visto la luz gracias a una de las becas Heracles 2016-2017 ofrecidas por el Departamento de Literatura Española de la Universidad de Córdoba para actividades formativas de Doctorado y Máster. Agradezco a los Profesores Andrea Baldissera (Università del Piemonte Orientale), Rafael Bonilla Cerezo (Universidad de Córdoba) y Paolo Tanganelli (Università degli Studi di Ferrara) la lectura y las sugerencias que aquilatan el ensayo.

2 Alonso (1975: 27-58).

3 Para profundizar, remitimos a la reciente edición firmada por Rico García (Jáuregui 2002).

4 Artigas Ferrando (1925: 400-467).

5 Ya en 1994, Joaquín Roses Lozano señalaba la necesidad de una edición del Examen: «[...] resulta lamentable que, a diferencia de lo que ocurre con el Antídoto e incluso con otros documentos menos destacados, no contemos con una edición actualizada del tratado apologético del Abad de Rute» (Roses Lozano 1994: 31); y en 2007: «Ya en mi libro sobre la poética de la oscuridad, publicado en 1994, reclamé la necesidad de una edición actualizada, útil y fiable de este importante documento de la polémica gongorina. Para empezar, aunque Artigas se basó en un solo testimonio, son más de seis los manuscritos conocidos que presentan copias del Examen.

Edad de Oro, XXXVI (2017), pp. 191-232, ISSN: 0212-042 - DOI http://dx.doi.org/10.15366/edadoro2017.36.012 
Conscientes de esta necesidad y gracias al estímulo del proyecto de investigación Édition digitale et étude de la polémique autour de Góngora, dirigido por Mercedes Blanco, nos hemos comprometido a firmar una edición crítica de la obra de Fernández de Córdoba que se publicará a lo largo de 2018. Para ello, una vez considerada la pluralidad de manuscritos a nuestro alcance, ha sido indispensable -diríamos que inevitable- la aplicación del método neolachmanniano, con la necesaria collatio de los testimonios, la localización de errores y la consiguiente identificación de familias textuales. En las páginas de este artículo resumimos los datos obtenidos durante la recensio, a partir de la descripción de los códices cotejados hasta la constitutio stemmatis.

\section{LOS TESTIMONIOS DEL EXAMEN}

\subsection{Biblioteca Nacional de España ${ }^{6}$}

ms. 3906 (citado A)

[Papeles varios gongorinos] - S. XVII, XII pp., $700 \mathrm{ff.,} 220$ x $155 \mathrm{~mm}$.

En el tejuelo del manuscrito se lee: «Don Martín de Ángulo / Égloga Fúnebre a Don Luis de Góngora»; y en una de las primeras páginas: «Manuscrito de D. Martín de Ángulo con varias poesías de D. Luis de Góngora y Argote». De hecho, en los primeros folios, aparece impresa dicha Égloga fúnebre a Don Luis de Góngora de versos entresacados de sus obras por Don Martín de Ángulo y Pulgar, natural de la ciudad de Loja.

Como se deduce de una nota que sigue al índice, debió de pertenecer a don Ambrosio de la Cuesta y Saavedra, canónigo de la Catedral de Sevilla. El índice nos proporciona toda la información relativa a las obras contenidas en el códice. En particular, además del Examen del Antídoto, que comienza en el folio 455, encontramos algunos poemas de Góngora y otros textos de la polémica, entre los cuales cabe citar:

1) Carta de Pedro de Valencia a Don Luis de Góngora en censura y juicio que hace de su poesía; 2) Discurso apologético de Pedro Díaz de Rivas sobre las poesías de Don Luis de Góngora; 3) Fábula de Polifemo y Galatea de Don Luis de Góngora; 4) Soledades de Don Luis de Góngora; 5) Censura a las lecciones solemnes que Pellicer hizo a las obras de Don Luis de Góngora; 6) Antídoto contra la poesía pestilente de Don Luis de Góngora por Don Juan de Jáuregui (perdido); 7) el

Durante 1996 estuve trabajando en esos materiales e inicié la edición del texto, pero diversas circunstancias paralizaron el proyecto, que quizá retome en los próximos años» (Roses Lozano 2007: 147).

6 Para la descripción física de los manuscritos actualmente conservados en la BNE, nos apoyamos también en el catálogo de dicha institución (s.n. 1984: 165, 184, 210, 411). 
mismo Examen; 8) unos Diálogos que ofrecen la exégesis de algunos textos gongorinos.

Características peculiares: el copista embute en el mismo texto las referencias a las obras latinas e italianas que cita Fernández de Córdoba y que en el resto de los testimonios aparecen como marginalia.

ms. 3726 (citado M)

[Obras de Góngora y referentes a él] - S. XVII, 343 ff., 215 x 150 mm.

Redactado con tintas diferentes por un mismo amanuense, el códice transmite varios textos de la polémica gongorina y algunas obras de Góngora. La letra es del siglo XVII, y la copia de los Discursos apologéticos de Díaz de Rivas (ff. 72-221) está fechada en 1624.

El Examen empieza en el folio $253 \mathrm{v}$, no presenta título y se divide en 43 epígrafes que articulan idealmente el tratado a medida que el autor pasa de una argumentación a otra.

El códice contiene:

1) Fábula de Acis y Galatea de Luis Carrillo Sotomayor; 2) Fábula de Polifemo a lo burlesco, de Alonso del Castillo Solórzano; 3) Fábula de Polifemo y Galatea en octavas; 4) Soledades; 5) Discursos apologéticos por el estilo de Polifemo y Soledades... de Pedro Díaz de Rivas; 6) Antídoto contra la pestilente poesía de las Soledades, aplicado a su autor, para defenderle de sí mismo, de Juan de Jáuregui; 7) Décima contra este Antídoto, que hizo Juan de Jáuregui contra las Soledades; 8) Contra el Antídoto y en favor de Luis de Góngora, por un curioso; 9) Examen del Antídoto ( $\sin$ título); 10) Cierta nota, de cierto advertente a este examen; 11) Una apología del señor don Francisco por una décima del autor de las Soledades; 12) Canción a la toma de Larache; 13) Anotaciones de Pedro Díaz de Rivas.

ms. 5566 (citado M1)

[Cancionero] - Ss. XVI y XVII, III-XI pp., 732 pp., 305 x 205 mm.

El códice presenta, en las primeras páginas, la «Tabla de lo que contiene este libro», y hasta la 193 transmite un cancionero con obras de diferente naturaleza. Interviene más de un amanuense: pp. III-XI y 1-193, letra del siglo XVI; pp. 199601, letra del siglo XVIII; desde la p. 603, distintos tipos de letras del siglo XVII. Se repite un índice de los contenidos, algo más detallado en las pp. 728-732.

Se trata de un codex descriptus del ms. 3726 de la misma Biblioteca. Por tanto, en buena lógica, el Examen del Antídoto (pp. 329-511) carece de título y se divide 
en 43 epígrafes. Generalmente, el copista sigue a pies juntillas su modelo, sin intervenir ni enmendar (quizá también por su escasa competencia).

El códice contiene:

1) El antedicho cancionero que incluye poemas de Diego Hurtado de Mendoza;

2) Fábula de Acis y Galatea de Luis Carrillo Sotomayor; 3) Fábula de Polifemo a lo burlesco de Alonso del Castillo Solórzano; 4) Antídoto contra la pestilente poesía de las Soledades, aplicado a su autor, para defenderle de sí mismo, de Juan de Jáuregui; 5) Contra el Antídoto y en favor de Luis de Góngora, por un curioso; 6) Examen del Antídoto (sin título); 7) Cierta nota, de cierto advertente a este examen; 8) Una apología del señor don Francisco por una décima del autor de las Soledades; 9) Canción a la Toma de Larache; 10) Anotaciones de Pedro Díaz de Rivas; 11) Otros poemas de Diego Hurtado de Mendoza y anónimos.

ms. 3803 (citado M2)

S. XVII, 109 ff., $200 \times 150 \mathrm{~mm}$.

Este códice, usado y transcrito por Miguel Artigas para su estudio de $1925^{7}$, solo transmite el Examen del Antídoto, atribuido aquí a Cristóbal de Salazar Mardones, el autor de la Ilustración y defensa de la Fábula de Píramo y Tisbe (1636). Encuadernación en pergamino. Al principio, un folio con distinta letra: «Contra lo que finge Virgilio que Numa Emperador fue discípulo de Pitágoras». El copista, muy atinado, demuestra también un discreto conocimiento de las lenguas latina e italiana.

\subsection{Biblioteca Universitaria de Salamanca ${ }^{8}$}

ms. 2006 (citado S)

S. XVII, 2 h., 377 ff., 1 h., 210 x 150 mm.

Tras pasar por la Biblioteca del Palacio Real de Madrid (n. 1323) y el Colegio Mayor de Cuenca (n. 63) ${ }^{9}$, este códice, en el que intervienen diferentes copistas, transmite, gracias a la labor de un solo amanuense, una copia de la obra de Fernández de Córdoba (186r-267r), erróneamente atribuida aquí a Francisco de Amaya $^{10}$ : «Apología por las Soledades contra el Antídoto. Escribiola el Doctor Francisco de Amaya».

El manuscrito contiene:

\footnotetext{
Artigas Ferrando (1925: 400-467).

8 Para la descripción física de los manuscritos actualmente conservados en la Biblioteca Universitaria de Salamanca, nos apoyamos en el catálogo de Lilao Franca (2002).

9 Véase Lilao Franca (2002: 341) y también Jáuregui (2002: LXXIII).

10 Véase la nota 43.
} 
1) Antídoto contra la pestilente poesía de las Soledades aplicado a su Autor para defenderle de sí mismo; 2) Anotaciones a las bellezas de el Polyphemo (Pedro Díaz de Rivas); 3) Anotaciones a la Soledad primera de Luis de Góngora (Pedro Díaz de Rivas); 4) Al maestro Lisarte de la Llana el licenciado Claros de la Plaça su discípulo, hijo de Llanos de Castilla y Plaça <contra la Jerusalén de Lope de Vega> (Juan de Jáuregui); 5) Un décima que comienza: «De Antídoto rotulado / este bote de veneno»; 6) Examen crítico de la canción que hiço Lope de Vega a la venida del duque de Osuna, dirigido al mismo auctor; 7) Respuesta de una carta que envió el duque de Osuna a don Octavio de Aragón, hijo de el duque de Terranova; 8) Carta de Busto de Villegas a Felipe II sobre la venta de vasallos, jurisdicción y rentas temporales de iglesias y monasterios. Toledo, 15 de julio de 1574; 9) el propio Examen de Fernández de Córdoba; 10) Apología por una décima del autor de las Soledades (Francisco Fernández de Córdoba); 11) Pragmática de don Cupido, rey de los ciegos, contra los desatinos del amor; 12) Informe de don Mateo de Lisón y Biedma, veinte y cuatro de Granada, a su Majestad en la audiencia que dio viernes 11 de junio de 1626 años, sobre la contradicción de la venta de vasallos.

ms. 2123 (citado S1)

S. XVIII, 191 ff., 1 h., 206 x 145 mm.

El códice, parcialmente descriptus del ms. 2006, perteneció a la Biblioteca del Palacio Real de Madrid (n. 833) y al Colegio Mayor de Cuenca (n. 362) ${ }^{11}$, y conserva, además del propio Examen (1r-169r), de nuevo mal atribuido a Francisco de Amaya, las siguientes obras:

1) Apología por una décima del autor de las Soledades (Francisco Fernández de Córdoba); 2) Pragmática de don Cupido, rey de los ciegos, contra los desatinos del amor.

\subsection{Biblioteca de la Fundación Bartolomé March de Palma de Mallorca}

\section{ms. 6454 (citado G)}

Es el manuscrito número 66 de los fondos bibliográficos de la biblioteca del Duque de Gor, sacado a la luz por Emilio Orozco Díaz y actualmente conservado en la biblioteca de la Fundación Bartolomé March en Palma de Pallorca. En una de las primeras páginas, se lee: «Del Colegio de la Comp(añí)a de Jh(esu)s de Granada». El Examen del Antídoto empieza en el folio 35r y termina en el 123r. Está escrito por una misma mano. La letra es de mediados del siglo XVII.

El códice contiene:

\footnotetext{
$11 \quad$ Véase Lilao Franca y Castrillo González (2002: 484).
} 
1) Antídoto contra la pestilente poesía de las Soledades aplicado a su Autor para defenderle de sí mismo; 2) Examen del Antídoto o Apología por las Soledades contra el Autor del Antídoto; 3) Apología por una décima del Autor de las Soledades; 4) Parecer de Don Francisco de Córdoba acerca de las Soledades a instancia de su Autor; 5) Advertencias de Andrés de Almanza y Mendoza para inteligencia de las Soledades de Don Luis de Góngora; 6) Carta escrita a Don Luis de Góngora en razón de las Soledades; 7) Respuesta de Don Luis de Góngora; 8) Carta de Don Antonio de las Infantas y Mendoza respondiendo a la que se escribió a Don Luis de Góngora en razón de las Soledades; 9) Don Luis de Góngora a la Soledad persuadiéndola que deje la Corte; 10) Décimas del mesmo; 11) Respuesta a las cartas de Don Luis de Góngora y de Don Antonio de las Infantas.

Características peculiares: presenta muchas lagunas en las citas latinas e italianas, o incluso las omite completamente.

\subsection{Biblioteca del Seminario de Vitoria}

ms. 88 (citado V)

[Papeles varios] - S. XVIII, $273 \mathrm{ff} ., 330$ x $220 \mathrm{~mm}$.

Conservado en la Biblioteca del Seminario Diocesano Vitoria-Gasteiz, este manuscrito recoge, en sus primeras páginas, solo una séptima parte del Examen ${ }^{12}$, bajo el título: Defensa de Góngora contra el Antídoto de Jáuregui. La letra es de mediados del siglo XVIII. En el margen derecho superior de la primera página, coincidiendo con la obra del abad de Rute, se lee: «Lo subrayado está escrito con lápiz por D. B. J. Gallardo, cuya letra conozco muy bien. A.».

El códice contiene:

1) Defensa de Góngora contra el Antídoto de Jáuregui; 2) 91 cartas de Góngora (copiadas el año 1771); 3) Compilaciones de las instrucciones del Oficio de la Santa Inquisición de Tomás de Torquemada; 4) Condiciones que el Consejo de Población, establecido en Granada, mandó observar a los nuevos pobladores de su reino, en fecha de 22 de agosto de 1573 en conformidad de lo que S. M. tenía mandado en 25 de septiembre de 1571; 5) Capitulos de la Real Renta de Población de 1595; 6) Real Cédula de 15 de noviembre de 1688 ordenando que el protector de Granada vea en primera instancia los pleitos de los pobladores del Reino de Granada; 7) Real Cédula de 12 de enero de 1712 sobre pleitos de bienes confiscados a los moriscos de Granada; 8) Petición de los “cristianos viejos" al Rey; 9) Cédula de Felipe II de 24 de febrero de 1571 incorporando al fisco real los bienes de los moriscos rebelados; 10) Comunicación de haber remitido por duplicado el informe de Matías Anglés y Gortari, Corregidor de Potosí, sobre la causa criminal contra Joseph de Antequera y narrando los sucesos ocurridos el día de su ejecución, 29

12 Más precisamente, el segmento textual coincide con Artigas Fernando (1925: 400-409). 
de julio de 1731;11) Copia de documentos referentes a la pretensión del Marqués de Mondéjar a tener asiento en la Iglesia mayor de Granada el día de la Candelaria; 12) Informe de Juan Lucas Larraga sobre la aleación de oro de la plata que viene de Potosí; 13) Copia de la sentencia dada el 1 de noviembre de 1779 por los comisarios nombrados por el Congreso de los Estados americanos; 14) Informe de Miguel Ripa fechado el 24 de mayo de 1749 en que censura el régimen de tributos vigentes; 15) Súplica al Rey Presbitero D. Diego de Torres Villarroel, catedrático de Matemáticas y Astrología en la Universidad de Salamanca; 16) Episodios de la Guerra de Sucesión; 17) Memoria de los regalos con ocasión del bautismo de un Príncipe; 18) Relación del valor líquido de las encomiendas de las tres Órdenes Militares; 19) Cargos que resultan del proceso contra Joseph Estevan.

Características peculiares: además de ser lagunoso, el segmento que transmite presenta numerosas omisiones.

\section{LA TRADICIÓN TEXTUAL}

2.1. ¿Errores de arquetipo?

La condición para demostrar la existencia de un arquetipo, el ejemplar perdido del que descienden todos los manuscritos conservados de un texto y «por encima del cual no es factible remontarse» (Tanganelli 2016:180) ${ }^{13}$, es la localización de al menos un error monogenético común a toda la tradición. En el caso del Examen del Antídoto de Fernández de Córdoba, no contamos con pruebas irrefutables de la existencia de semejante códice y, en consecuencia, teóricamente podría caber la remota posibilidad de que toda la tradición derive de un original ${ }^{14}$ que, a la luz

13 Alberto Blecua, en realidad, aplica este tecnicismo incluso a códices conservados: «Con el término arquetipo se aludirá a un códice o impreso perdido, $X$, o conservado, $A, B$, $C$, etc., que transmita errores comunes a todos los testimonios» (Blecua 2001: 71). «Si chiama archetipo la copia non conservata, guastata da almeno un errore di tipo congiuntivo, alla quale risale tutta la tradizione» (Stussi 1994: 128). Particularmente sugestivo resulta el estudio de Paolo Trovato (2005: 1-18), quien, volviendo sobre la distinción entre un archetipo $_{1}$, el «esemplare dell'opera apprestato dall'autore per la divulgazione, esemplare ufficiale», y un archetipo $o_{2}$, la «copia non conservata guastata da almeno un errore di tipo congiuntivo, alla quale risale tutta la tradizione» (Trovato 2005: 12), insiste en la necesidad de mantener separados los ámbitos conceptuales de la crítica del texto y de la historia de la tradición: «In altre parole, l'archetipo (non so se già in Madvig, sicuramente in Maas e nella tradizione filologica successiva) è un punto dello stemma oltre il quale la tradizione superstite non consente di risalire e di norma non ha niente a che vedere con le vicende remote della tradizione, ma solo con l'insieme dei manoscritti oggi disponibili, individuati dal filologo in fase di recensio» (Trovato 2005: 12). Para profundizar, véase también Trovato (2014: 63-67).

14 «En general, cuando no se logra demostrar la existencia de un arquetipo, hay que asumir que la tradición deriva directamente del original (que, por supuesto, puede ser un original en movimiento), y, en consecuencia, no se podrá descartar que las variantes adiáforas de las ramas altas 
de las pequeñas corruptelas presentes en todos los manuscritos, debería identificarse al menos con un autógrafo redactado de forma apresurada, o tal vez con un idiógrafo. Sin embargo, los ocho errores compartidos por todos los testimonios que nos traemos entre manos nos inducen a formular una hipótesis distinta, ya que, aun siendo de naturaleza supuestamente poligenética, su número se antoja elevado para un texto tan breve: de hecho, hemos detectado hasta ocho innovaciones comunes; $y$, además, en algunos casos resulta sumamente difícil pensar que se trate de coincidencias casuales (fallos cometidos de forma independiente por diferentes copistas) o de lapsus calami del mismo autor. A fin de cuentas, la linde entre monogénesis y poligénesis no siempre salta a la vista, toda vez que el grado de monogénesis de determinadas corruptelas depende asimismo de las características concretas de la tradición ${ }^{15}$. En el caso que nos ocupa, el corolario más económico, por tanto, es que existiera un arquetipo $\Omega$ entre el original y los apógrafos conservados; lo cual conllevaría, como principal secuela, la imposibilidad de detectar, dentro de esta cultísima tradición, variantes de autor, ni menos todavía distintas redacciones del texto del abad de Rute ${ }^{16}$.

La primera de dichas innovaciones es la presencia de "eso" en lugar de "eslo" en el fragmento que sigue:

puedan ser del mismo autor (o, más en general, que los testimonios conservados desciendan de diferentes redacciones 'originales')» (Tanganelli 2016: 184).

15 Con respecto al concepto de poligénesis, a sus condiciones y a sus límites, remitimos al estudio y taxonomía de Caterina Brandoli (2007: 99-214). Paolo Trovato reproduce la clasificación de Brandoli (Trovato 2014: 113) insistiendo en su carácter probabilístico y en la dificultad de distinguir entre innovaciones poligenéticas y monogenéticas, determinada por el diferente grado de tolerancia que los distintos géneros literarios presentan hacia algunos tipos de error: «I would add that, in general, the difficulty of spotting significant errors depends on the fact that every literary genre has a different degree of tollerance for certain types of error. The textual critic should thus distinguish noise from significant errors case by case. While in major poets such as Virgil or Dante, the mere omission of a disyllable, being prosodically unacceptable, is usually a significant error, in thirteenth-century copies of prose Latin guides to the Holy Land neither the addition nor the omission of an epithet, or the abbreviation or extension of a scriptural quotation, is genealogically significant» (Trovato 2014: 115). De forma análoga, Blecua sostiene que no se pueden distinguir con seguridad los errores separativos de los meramente conjuntivos: «si nosotros detectamos la presencia de un error común separativo, también un copista pudo advertirla. En la práctica, aunque tales errores existen, resulta imposible demostrar con certeza absoluta su presencia. Podemos encontrar, aunque no es fácil, en las ramas bajas y aun en las altas, errores conjuntivos, pero en lo que se refiere a los errores separativos no podemos sino movernos en el terreno de lo probable» (Blecua 2012: 407). En efecto, tanto en la distinción entre errores monogenéticos y poligenéticos, como en la en ocasiones borrosa frontera entre separativos y conjuntivos, no es factible rebasar el campo de las probabilidades y siempre habrá que formular la hipótesis más económica para explicar la fenomenología de las corruptelas.

16 López Viñuela (1998: 377-388) defiende la hipótesis de las dos redacciones reconstruibles a través de los testimonios conservados. 
[A431] ${ }^{17}$ Aunque, si mira vuestra merced -sin antojos de apasionado alinde- los defectos de este poema, confesará que no es tan oscuro -como eslo [eso A M M1 M2 S esso G ese S1 (V lagunoso)] su estilo-, pues se acomoda a los sujetos de que trata, pues tiene tanto de energía, o evidencia, o perspicuidad, que así la llama Cicerón...

La polémica literaria, nacida a raíz de la difusión de las obras mayores de Góngora, se desarrolló en torno a las dicotomías ars e ingenium, docere y delectare $\mathrm{y}$, sobre todo, res y verba ${ }^{18}$. Dicha controversia, como es sabido, fue protagonizada por dos bandos opuestos: por un lado, los llanistas, para los cuales la poesía solo podía admitir la oscuridad de las cosas, de la materia tratada (res); por otro, los cultistas, defensores de una forma lingüística nueva, difícil y oscura (preeminencia de los verba). Desde luego, para defender a Góngora de las pullas de Jáuregui, al abad de Rute no le quedaba otra que alistarse en el partido cultista y demostrar que la grandeza de las Soledades se cifraba justo en la capacidad para deleitar ocultando con un estilo grandilocuente res muy sencillas y, en ocasiones, triviales. Así las cosas, se antoja lógico suponer que en el original -o por lo menos en la redacción ideal del autor-figurara "eslo" y no "eso" (o "ese", enmienda del copista de $\mathrm{S} 1$ que corrige ope ingenii).

La segunda corruptela común a todos los testimonios es el error "Égloga II" por "Égloga I" en un pasaje donde se alude evidentemente a los versos iniciales de la Égloga primera de Garcilaso, dedicados al virrey de Nápoles, don Pedro de Toledo, y citados también por Jáuregui en su Antídoto:

[A407] Vuestra merced quisiera que le aplicara el autor de las Soledades otra ocupación y virtud ilustre, competente a tal señor -a imitación de Garcilaso en la Égloga I [Egloga II A ecgloga 2a G M2 egloga 2a M M1 V eglog(a) 2a S S1]-, y esta fuera -aunque loable en príncipes- muy accidental, como nada heroica en lo militar ni en lo civil.

Igualmente poligenético podría considerarse el error "baptizarán" en lugar de "baptizará", a resultas de la lectura equivocada de un titulus:

[A406] Si en la primera, que sola hoy ha salido a luz, este mancebo está por baptizar, tenga vuestra merced paciencia que en la segunda o en la tercera se le baptizará [baptizaran A baptizarán G V bautizaràn M M1 baptiçaran M2 vaptiçaran $\mathrm{S}$ baptizaràn $\mathrm{S} 1$ ] y sabrá su nombre.

17 En espera de nuestra edición, con el fin de ofrecer al lector referencias "topográficas" lo más precisas posibles a propósito de los fragmentos examinados, indicamos entre corchetes su localización en la transcripción de Artigas Ferrando (1925: 400-467).

18 Véase Darst (1985: 51-82). Véase también López Bueno (2000: 13-29), Roses Lozano (1994: 66-187), Orozco Díaz (1973: 169-271).

Edad de Oro, XXXVI (2017), pp. 191-232, ISSN: 0212-0429 
A estas corrupciones, hay que añadir otras dos innovaciones, que, aunque se ciñen una vez más al cambio de un grafema, nos parece algo más difícil que se hayan producido de manera independiente en cada testimonio de la tradición:

[A423] Pues para mí, tengo por sin duda que hablaron de un mismo Euforión el orador y el poeta latino, porque si bien hubo otro de este nombre $-\mathrm{y}$ poeta fue trágico y natural de Atenas, hijo de Esquilo el trágico-, el de Calcis tuvo por padre a Polimneto, por condiscípulos a Lácidis y Prítanis (filósofos), y Arquébulo [Archebuto A G M M1 M2 Arcohebuto S Archoebutto S1 (V lagunoso)] Tereo (poeta), por fautores a la mujer de Alejandro, rey de Eubea, hijo de Crátero, y después a Antíoco el Grande, rey de Siria, de cuya biblioteca tuvo cargo.

\begin{abstract}
$* * *$
[A445] Virgilio al menos así lo hizo: ¿cuántas y cuántas palabras hallará vuestra merced repetidas en sus obras cincuenta y cien veces? ¿Cuántas en la de Horacio y otros? ¡Hasta tentejuela [tentejuelo A G M M2 S tentezuelo M1 tentejullo S1 (V lagunoso)]! Hablen el índice virgiliano de Nicolás Eritreo y el horaciano de Tomás Trectero y callará vuestra merced en esta materia por cien años.
\end{abstract}

En el primer caso, basta considerar la fuente utilizada por el abad de Rute, es decir, la Suda o Suidas, enciclopedia bizantina que, acerca de Euforión, reza: «Euphorion, Polymneti filius, e Chalcide Euboeae, condiscipulus in philosophicis, Lacydis et Pritanidis. In poeticis vero, Archebuli Thaeraei Poetae, cui et in deliciis fuerit» (Suidae: 349 ).

Por lo que se refiere al segundo pasaje, en cambio, el Corpus Diacrónico del Español (CORDE) no registra el uso del término "tentejuelo" en ningún documento ${ }^{19}$. En cuanto a la voz "tentejuela", compuesta de "ten" y "tejuela" según el Diccionario Alemany y Bolufer (1917), se localiza en la novela La pícara Justina de Francisco López de Úbeda; y la locución adverbial "hasta tentejuela" se halla en tres diccionarios de mediados del XIX («hasta no poder más, con todo extremo», Salvá 1846). Por este motivo, parece razonable considerar la lección "tentejuelo" una innovación.

Ahora bien, los errores que definitivamente nos inducen a apostar por la existencia del arquetipo son tres. Se trata, respectivamente, de la inversión "si no carga y asombro", en la transcripción del verso 308 de la Soledad primera («si carga no y asombro») ${ }^{20}$; y de dos corruptelas que, aun ciñéndose al cambio de apenas

\footnotetext{
19 A pesar del resultado negativo de la consulta del banco de datos, la expresión "a tentejuelo" aparece en la novela peregrina El perro y la calentura de Pedro Espinosa (2010: 311).

20 Consideramos poco probable que dicha inversión figurara en el ejemplar de las Soledades utilizado por el abad de Rute, puesto que en el Parecer este mismo verso se cita de manera correcta: «Dice luego vuestra merced de los muchos conejos que uno traía a cuestas: "Trofeo ya su número
} 
uno o dos grafemas, difícilmente pueden haberse dado de manera independiente en distintos códices. La primera de estas es la corrupción "los gigantes" en lugar de "las gigantas" 21 :

[A412] Así también diremos a la vela del navío, o sea - por solo servir a vuestra merced- al navío mismo, "Clicie del viento»; no porque camine buscando al sol, ni porque lleve aquellos desmesurados florones que las gigantas [los gigantes $\mathbf{A}$ G M M1 M2 S S1 (V lagunoso)] o girasoles, sino porque de la manera que estos, mirando al sol, se gobiernan por él, así la vela mira al viento y por él se gobierna, si bien para huirle y darle espaldas como el heliotropio para seguir a su querido, el sol, y andarse tras él.

La segunda innovación $-\mathrm{y}$, en nuestra opinión, última prueba de la existencia de $\Omega$ - es, en cambio, la glosa marginal "Égloga" en lugar de "Elegía”, presente en todos los testimonios para remitir al verso 13 de la Elegía cuarta de Herrera, «Del ancho mar el término infinito» (Herrera 1985: 399):

\section{[A413] Elegía IV [Egl. I A Ecglo. 4 G Egloga 4a M2 Herre eglo. M M1 Herrera Eg $>$ o $<\log .4$ S Herrera Eglog. 4 S1 (V lagunoso)]}

En este lugar, de hecho, resulta bastante remota la posibilidad de un origen poligenético, aun suponiendo que la innovación se produzca a partir de la errónea lectura de la frecuente abreviatura "eleg." por "elegía".

\subsection{La familia $\beta$}

Entre los datos más relevantes que nos brinda la collatio, destacan una serie de errores comunes en seis de los ocho manuscritos conservados que, por ser conjuntivos y separativos a la vez ${ }^{22}$, nos llevan a suponer que estos ejemplares constituyan una familia y deriven, por consiguiente, de un único subarquetipo $\beta$.

es a un hombro / si carga no y asombro"» (BFBM, ms. 18/10/11: Parecer de Don Francisco de Córdoba acerca de las Soledades a instancia de su Autor, f. 143v).

21 Se trata evidentemente de una trivialización, puesto que la voz "giganta" equivale a «yerba, lo mismo que girasol» según la definición del Diccionario de la Lengua Castellana de la Real Academia Española de 1803.

22 «Requisito necesario para poder aplicar el método neolachmanniano es la individualización de familias textuales. Para aislar un grupo, precisamos al menos de un error común, es decir, una corruptela a la vez conjuntiva y separativa; o mejor dicho: un error conjuntivo con un grado de separatividad que el filólogo estime adecuado con respecto al tipo de transmisión que presupone» (Tanganelli 2016: 185).

Edad de Oro, XXXVI (2017), pp. 191-232, ISSN: 0212-0429 
La primera de dichas innovaciones conjuntivas, que poseen un grado de separatividad significativo con respecto al testimonio A, el cual quedaría, por tanto, fuera del grupo $\beta$, es la siguiente:

[A460] Y aunque no ha faltado quien haya dicho que no está obligado a sujetarse, pues, como príncipe que hoy es de la poesía española, puede dar leyes sin sujetarse a recibirlas -conforme a la ley princeps (D. de Legibus)-, él, por su modestia, juzga que debe pasar por ellas ajustándose en esto a la ley digna vox (C. de Legibus) y yo que maravillosamente las ha guardado, como ha parecido tantas y tantas veces por testimonio de autores tan graves.

digna vox A ] tigna (vox om.) G digna (vox om.) M M1 M2 S S1 (V lagunoso) C. de Legibus A ] en el mesmo titulo G. (de legibus om.) $\mathbf{G}$ en el mesmo titulo C. (de legibus om.) M M1 M2 en el mesmo (mismo S1) titulo (de legibus om.) S S1 (V lagunoso)

La segunda ley aludida en el fragmento corresponde, sin duda, a una constitución de Valentiniano III (C. 1, 14, 4), desmembrada en el Codex Iustinianus ${ }^{23}$, comúnmente conocida como digna vox, cuya finalidad era impedir que el emperador privilegiase y absolviese de las leyes a los príncipes ${ }^{24}$. Es lógico suponer que la caída de "vox" se haya originado en un único ejemplar y que luego se haya transmitido a sus descendientes. Asimismo, la innovación "en el mismo título" se antoja como una reelaboración errónea de $\beta$, ya que las dos leyes suelen encontrarse en títulos diferentes del Corpus: la primera en el Digesto y la segunda en el Codex propiamente dicho.

Otros errores que confirman la existencia de la familia $\beta$ son un par de corruptelas en la transcripción de algunos nombres propios:

[A423] ...y lo mismo sienten Pedro Victorio en sus Varias y Roberto Estéfano en su Thesauro.

Victorio ] Victor G M M1 M2 S S1 (V lagunoso)

[A425] Imitación es la poesía y su fin es ayudar deleitando. Si este fin se consigue en la especie en que se imita, ¿qué le piden al poeta? ¿Guardan hoy, por ventura,

23 Citamos la ley tal como se lee en el estudio de Diego Quaglioni (2007-2008: 55-67): «Digna vox maiestate regnantis legibus alligatum se principem profiteri: adeo de auctoritate iuris nostra pendet auctoritas. Et re vera maius imperio est submittere legibus principatum. Et oraculo praesentis edicti quod nobis licere non patimur indicamus» (Quaglioni 2007-2008: 55).

24 Véase Quaglioni (2007-2008: 55). 
la tragedia y la comedia el modo mismo que en tiempo de Tespis o de Éupolis? No, por cierto.

\section{Éupolis A ] Eupolo G M M1 M2 S S1 (V lagunoso)}

En estos pasajes, resulta lógico atribuir a un único copista las lecturas erróneas de "Pedro Victorio" y de "Éupolis", humanista italiano del siglo XVI ${ }^{25}$ y comediógrafo griego del siglo v a. C. ${ }^{26}$, respectivamente.

Corroboran la existencia de $\beta$ un rico abanico de omisiones, tanto de palabras como de segmentos textuales más extensos, que atañen principalmente a las citas latinas, y también la transcripción incorrecta de algunos fragmentos procedentes del texto del Antídoto de Jáuregui ${ }^{27}$ :

[A436] «Estos modos - dice vuestra merced- son vilísimos, como cuando el vulgacho dice "hubo tanta dama", "tanto caballero", "tanta de la merienda"»"

tanta de la merienda A ] mucha de la merienda G M M1 M2 S S1 (V lagunoso) $)^{28}$

[A453] Dice vuestra merced luego: «Notable escrúpulo tuvo vuestra merced cuando tocó aquella similitud del carbunclo, pues dijo: "Si tradición apócrifa no miente". Dejado que el verso es nada poético, el melindre es graciosísimo para quien toca mil mentirosas fábulas tan sin cuidado».

25 Piero Vettori (1499-1585), castellanizado Pedro Victorio, fue un humanista florentino de la primera mitad del siglo XVI, filólogo y lector de griego y latín en el studium de Florencia. Se dedicó a ediciones y comentarios de obras de Cicerón, Terencio, Aristóteles, Platón, Esquilo y, sobre todo, de la obra completa del poeta italiano Giovanni della Casa. Véase Asor Rosa (1991: 1810-1811).

26 Éupolis (446-h. 411 a. C.) fue uno de los poetas de la así llamada Comedia Antigua, junto con Cratino y Aristófanes. De sus comedias, entre las cuales destacan Marikas y Demoi, han llegado hasta nosotros solo algunos fragmentos. A propósito de la trayectoria biográfica y literaria de Éupolis, véase la monografía de Storey (2003).

27 Para el cotejo con la obra de Jáuregui usamos principalmente el texto transmitido en el ms. 6454 de la Biblioteca de la Fundación Bartolomé March de Palma de Mallorca. Este testimonio parece ser el más cercano, entre los conservados, al ejemplar que el abad de Rute debió de emplear durante la redacción de su respuesta. Esta hipótesis se funda en un error presente en este testimonio y comentado irónicamente por Fernández de Córdoba: «Los Lestrigones, pueblos fueron de Italia y de Sicilia, confesámoslo, no reparando en que algún ejemplar de los de vuestra merced por error del copista tiene Cilicia». Véase el aparato de variantes de la edición crítica del Antídoto de Jáuregui (2002: 123).

28 Tanto la lección "mucha de la merienda" como la omisión de "tan sin cuidado" de $\beta$ no se registran en ninguna de las copias conservadas del Antídoto (Jáuregui 2002: 101-102, 114); por eso deben considerarse erróneas. 
tan sin cuidado A ] om. G M M1 M2 S S1 (V lagunoso)

\begin{abstract}
$* * *$
[A436] Dice luego vuestra merced: «Igual hermosura tienen aquellos tres versitos como tres perlas: "La orza contenía / que un montañés traía. / No excedía la oreja, etc."»

tres A ] om. G M M1 M2 S S1 (V lagunoso)

La orza contenía ... la oreja A ] y refiere los versos G M M1 M2 S S1 (V lagunoso)
\end{abstract}

En el postrer ejemplo, la omisión de los versos de la Soledad primera, citados e irónicamente comentados por Jáuregui, y su sustitución por "y refiere los versos", dejan el pasaje incompleto y el objeto de la argumentación resulta incomprensible.

Algo parecido ocurre asimismo con una latinización de Aristóteles y con otros versos tomados de las Soledades:

[A432] Porque comoquiera que las palabras no solo son señales de los conceptos -conforme al filósofo, «voces sunt signa conceptuum»-, sino vestiduras de ellos, han de ser ajustadas a su talle...

voces sunt signa conceptuum A ] om. G M M1 M2 S S1 (V lagunoso)

[A435] Haga vuestra merced unas ordenanzas confirmadas de Apolo y graduarlas hemos aquí de Dios y del rey, que un verso tan significativo y de tanta energía, «Pasos otro dio al aire al suelo coces», se dé por de caballeriza. [...] Que el siguiente verso, «Advocaron así toda la gente», sea de tribunal no es maravilla, pues donde había juzgado de juegos y premios, no pudo faltar tribunal de jueces...

Pasos otro dio al aire al suelo A ] om. G M M1 M2 S S1 (V lagunoso) Advocaron así toda la gente A ] om. G M M1 M2 S S1 (V lagunoso)

Además de estos errores probablemente monogenéticos, se detectan una haplografía y numerosas innovaciones, las cuales podrían haberse producido de forma poligenética. Nos limitamos a señalar solo unos cuantos:

[A440] he tenido y tengo por cierto que, cuidando más como maestro de retórica de las figuras de las sentencias que de las de las palabras A ] (de las om.) de las palabras G M M1 M2 S S1 (V lagunoso) 


\section{$* * *$}

[A403] Petronio Árbitro, introduciendo a Encolpio, triste por haberle dejado su compañero Gitón A ] Eucolpio G M M1 M2 S S1 (V lagunoso)

[A437] no usó de versos repetidos, intercalares o amebeos A ] amaveos $\mathbf{G}$ amabaeos M M1 amabeos M2 S S1 (V lagunoso)

[A438] En cuanto a los versos de amebeos del epitalamio de las Soledades ] amaveos G amabaeos M M1 amabeos M2 S S1 (V lagunoso)

Las corruptelas de $\beta$ nos inducen a excluir la posibilidad de que este, o uno de sus descendientes, constituya el modelo para A (y como veremos más adelante, para V).

El manuscrito A, por su parte, presenta una serie consistente de lecciones características y de errores separativos que implican la imposibilidad de una derivación inversa: A no pudo ser el modelo de $\beta$. La naturaleza de dichas innovaciones individuales es heterogénea: omisiones, trivializaciones, inversiones, sustituciones y corrupciones de diferente fenomenología. Seleccionamos algunos de los casos más llamativos:

[A407] Cuán loable entretenimiento o ejercicio sea el de la caza en los grandes señores, pues lo confiesa vuestra merced, no hay para qué traer autoridades de Jenofonte ni de Platón para probarlo ni comprobarlo con la de estadistas modernos, entre los cuales el Fraqueta, en su Príncipe, y Juan Chokier, en su Tesoro de aforismos politicos, lo tratan bien.

con la de estadistas G M M1 M2 S S1 ] con los escritores A con (om. la) de estas listas $\mathbf{V}$

[A408] Al cuerpo ayuda notablemente, habituándole a fatigas y sudores, tirocinio maravilloso de la milicia, respecto de lo cual dijo el otro rútulo que Virgilio introduce loando su nación: «Venatu invigilant pueri silvasque fatigant».

nación G M M1 M2 S S1 V ] nacimiento A

Dejando a un lado la obvia trivialización "con los escritores" de A, en el segundo fragmento, el abad de Rute transcribe el v. 605 del noveno libro de la Enei$d a$, en el que el rútulo Numano, «como representante genuino de la raza itálica, define a su pueblo como duro, austero, habituado a la caza y a la guerra, es decir, como gente de acción, y lo opone a los griegos $\gg{ }^{29}$. Considerando la materia tratada

29 Citamos a Vicente Cristóbal en su Introducción a Virgilio (1992: 71). 
y el contexto del cual procede la cita virgiliana, cabría interpretar la lección "nacimiento" - poco coherente con el concepto de genus evocado por Virgilio («durum a stirpe genus natos ad flumina primum / deferimus saevoque gelu duramus et undis; venatu invigilant pueri silvasque fatigant $\rangle^{30}$ )- como una innovación de A, quizá a resultas de la lectura errónea de la abreviación de "nación" en su modelo.

Significativas también las siguientes corruptelas:

[A444] Pasadero es también Hernando de Herrera, pero a cada paso incurre en el pecado mismo, diciendo: «süave», «ansïoso», «orïente», «varïar», «rocïado», «glorïoso», «glorïosa», «rocïada», «cambïase», «ocïoso», «victorïoso», «süavemente», «rabïoso», «impetüoso», «espacïoso», «brïoso», «superïor», «ocïosa», «trïunfando», «inferïor», «impetüosa», «victorïosa», «vïolento», «pïadosa», «piedad», «invidiosos», «trïunfos», «invidioso», «quietud», «dïamante», «glorïosas», «pluvïoso». Ve aquí vuestra merced que exceden ya en número los que nota por demasiados en nuestro poeta.

glorïosa ... ocïoso M M1 M2 S S1 ] om. A (glorïosa, rocïada om.) cambïase, ocïoso $\mathbf{G}(\mathbf{V}$ lagunoso $)$

que exceden ... por demasiados G M M1 M2 S S1 ] que siendo estas vozes usadas veinte i ocho vezes ecceden (ya $\mathrm{om}$.) en número a las que nota por demasiadas $\mathbf{A}$ (V lagunoso)

En su intento de defender a Góngora de las saetas de Jáuregui relativas al empleo arbitrario de la diéresis, Fernández de Córdoba inserta un elenco de 32 palabras, en las cuales Fernando de Herrera optaría por esta licencia, separando por tanto el diptongo. Ahora bien, Herrera, a lo largo de su corpus poético, utiliza efectivamente unas cuarenta voces con diéresis ${ }^{31}$; pero de estas tan solo 25 coinciden con el listado del abad de Rute. Al margen de dicha discrepancia, parece manifiesto, en cualquier caso, el error de A, porque su copista elimina cuatro términos sin motivo, tratándose de palabras que figuran con diéresis en la edición crítica del poeta sevillano ${ }^{32}$. Este dato nos obliga a juzgar erróneas las lecciones de dicho testimonio y a considerar "siendo estas vozes usadas veinte i ocho vezes" una interpolación del manuscrito A.

30 Virgilio (2009: 284). En la traducción de Vicente Cristóbal: «Raza de dura estirpe, comenzamos llevando nuestros hijos al río apenas nacen / a que los curta su corriente helada. / De niños velan ya atentos a la caza y no dan punto de reposo al bosque» (Virgilio 1992: 428).

31 En particular, la edición consultada para este análisis es la de Cristóbal Cuevas (Herrera 1985).

32 Es preciso recordar que la circulación de varias ediciones de la obra del sevillano, además de la auténtica del propio Herrera (1582) y de la de Pacheco (1619), con grafías en ocasiones diferentes, no permiten definir con exactitud cuál sería el texto del que disponía Fernández de Córdoba. A propósito de las circunstancias de redacción de la poesía herreriana y de la controvertida edición de Pacheco, véanse, entre otros, Montero Delgado (2014: 2-14) y Herrera (1985: 87-99). 
A continuación, reproducimos otras innovaciones de A que, aun con un grado de separatividad nada despreciable, confirman la independencia de $\beta$ :

[A400] ha de mancharse quien tocare la pez G M M1 M2 S S1 V ] tratare A [A401] dice la Sabiduría G M M1 M2 S S1 V ] donde A

[A409] las paredes de muchos sagrados templos G M M1 M2 S S1 ] n(uest)ros A (V lagunoso)

[A411] ¿qué resulta de obsceno o sucio sonido o sentido? G M M1 M2 S S1 ] obscuro A (V lagunoso)

[A411] el campo, que no pisan alas hierba G M M1 M2 ] aun la A a la S S1 (V lagunoso)

[A416] no alcanza la más profunda meditación hallarles fondo G M M1 M2 S S1 ] a dalles $\mathbf{A}$ (V lagunoso)

[A452] y a lo del Epitalamio de Paladio y Celerina G M M1 M2 S S1 ] Serena A (V lagunoso)

Finalmente, cabe mencionar una serie de omisiones evidentemente voluntarias del copista de A, que deja unos espacios en blanco, los cuales, además de ratificar lo que acabamos de sostener, nos obligan asimismo a suponer que estuviera trasladando un modelo plagado de corruptelas y de difícil lectura. Además, es interesante observar que el amanuense señala en los márgenes, con una secuencia de números del 1 al 8, las lagunas de dicho ascendiente en correspondencia con las citas latinas o italianas, posiblemente con la intención -frustrada-de subsanar más tarde estos lugares acudiendo a las fuentes o, quizá, utilizando otro ejemplar del Examen:

[A401] Lo primero en que prueba vuestra merced la actividad y fineza de su Antídoto G M M1 M2 S S1 V ] la ( actividad om. dejando un espacio) y fineza A [A405] È forse assai che di Savona ai liti G M M1 M2 S S1 ] om. dejando un espacio A (V lagunoso)

[A405] Care selve beate G M M1 M2 S S1 ] om. dejando un espacio A (V lagunoso)

[A425] Mostrolo en sus obras el Ariosto y enséñanlo en las suyas los que le defienden: Josefo Malatesta, Francisco Patricio, Horacio Ariosto, y toda la Academia de la Crusca G M M1 M2 S S1 ] om. dejando un espacio A (V lagunoso)

[A431] como queda probado a juicio mío y después de Aristóteles G M M1 M2 S S1 ] a juicio de (deja un espacio) i mio A (V lagunoso)

[A435] «et aspera agili saxa calcantem pede» G M M1 M2 S S1 ] om. dejando un espacio y pone 1 en el margen $\mathbf{A}$ (V lagunoso)

[A436] pues Plauto dijo: «Hem, a crasso infortunio» G M M1 M2 S S1 ] om. dejando un espacio y pone 2 en el margen $\mathbf{A}$ (V lagunoso)

[A438] y luego «preparata», «destinata», «già promessa», «desïata» G M M1 M2 S S1 ] om. dejando un espacio y pone 3 en el margen A (V lagunoso) 
[A443] «Iv'era il curïoso Dicearco» G M M1 M2 S S1 ] om. dejando un espacio y pone 4 en el margen $\mathbf{A}(\mathbf{V}$ lagunoso)

[A443] El Guarini en el Pastor fido: «trïonfar che d'un teschio» G M M1 M2 S S1 ] om. dejando un espacio y pone 5 en el margen $\mathbf{A}$ (V lagunoso)

[A447] «Sei lustri non reggesti il crine e 'I mento» G M M1 M2 S S1 ] om. dejando un espacio y pone 6 en el margen $\mathbf{A}$ (V lagunoso)

[A447] «E sparge l'alba dal celeste grembo» G M M1 M2 S S1 ] om. dejando un espacio y pone 7 en el margen $\mathbf{A}$ (V lagunoso)

[A454] «con Proserpina, a cui l'inganno è teso» G M M1 M2 S S1 ] om. dejando un espacio y pone 8 en el margen $\mathbf{A}(\mathbf{V}$ lagunoso)

[A462] «L'America si parte ancora essa in due grandissime peninsole... G M M1 M2 S S1 ] om. dejando un espacio A (V lagunoso)

[A462] «Questa penisola del nuovo mondo tutta quasi sporta nel mezzogiorno...

G M M1 M2 S S1 ] om. dejando un espacio A (V lagunoso)

\subsection{La colocación de $\mathrm{V}$ y el subarquetipo $\alpha$}

La fragmentariedad de $\mathrm{V}$, que aproximadamente transmite solo una séptima parte del texto del Examen, representa un límite significativo para la colocación del mismo códice en el proceso de reconstrucción genealógica. Con todo, la localización de algunas innovaciones que comparte con $\beta$, junto con varios errores separativos de ambos ejemplares, nos permite conjeturar la existencia de un modelo común $\alpha$.

La primera de dichas innovaciones conjuntivas es la sustitución, sin duda monogenética, de "exponi”" por "cantari" en el verso de Horacio:

[A401] «Versibus exponi tragicis res comica non vult»

exponi A ] cantari G M M1 M2 S S1 V

Las ediciones del Ars poetica consultadas ${ }^{33}$ no registran en ningún testimonio cotejado la variante "cantari” en el v. 89, traído a colación por el abad de Rute. De ahí que nos decantemos por excluir que esta lección pudiera circular en ediciones de la época.

Se añaden a este error dos corruptelas más: la omisión de "fuisse" en el fragmento citado de la oración ciceroniana Pro P. Quinctio ("quod si tu iudex nullo

Consultamos dos de las ediciones más autorizadas que, aun cotejando respectivamente 37 (Horacio 1984: 296) y 17 (Horacio 1985: 314) de los testimonios más acreditados entre los centenares de ejemplares manuscritos e impresos conservados, no registran de hecho ningún tipo de variante por lo que atañe al verso que nos ocupa. No descartamos que la lección "cantari" sea el resultado de una glosa didascálica o léxica intercalada en el texto por el copista de $\alpha$. 
praesidio fuisse videbere contra vim et gratiam solitudini atque inopiae") $)^{34}$, y la transcripción errónea -y teóricamente poligenética- del primer verso de la Égloga I de Garcilaso de la Vega ("el dulce lamentar de los pastores" en lugar de "el dulce lamentar de dos pastores") 35 .

Por lo que atañe a los errores separativos de V, bastará como ejemplo una de las numerosas omisiones que afectan tanto a extensos fragmentos del texto castellano como a citas latinas e italianas:

[A404-405] Y estaba, o se finge estar, entonces poblada y frecuentada por extremo de pastores y zagales y aun de villajes. Últimamente en la égloga octava: «Forse che per fuggir la solitudine, / or cerchi le cittadi», etc.

El Chiabrera en la canción que hizo a Colón: «Non perché umile in solitario lido / Ti cingano, Savona, anguste mura».

Y en otro lugar: «E forse assai che di Savona ai liti / in solitaria riva / altri ne canti lagrimoso e scriva».

Siendo así que la rivera de Saona no es solitaria, pues la ciudad está junto a ella y acuden de ordinario vajeles a ella.

en la égloga ... e scriva A G M M1 M2 S S1 ] om. V

Por lo que se refiere a posibles innovaciones de $\beta$ que tengan valor separativo con respecto a $\mathrm{V}$, dado el carácter fragmentario de este códice, la localización de verdaderos errores resulta casi una quimera o, cuando menos, una empresa bastante complicada. De hecho, los únicos datos que nos inducen a conjeturar la independencia de $\mathrm{V}$ son una consistente serie de loci en los que este testimonio coincide con A en lecciones adiáforas que, evidentemente, debemos remontar al arquetipo o -más arriba- al original. Seleccionamos solo algunas de ellas:

[A400] cuando me encontré con sendos trapos A V ] (me om.) encontré (con om.) G M2 M M1 S S1

[A401] luego ha de serlo en sí o en sus obras A V ] halo de ser G S S1 lo à de ser $\mathbf{M}$ lo ha de ser M1 a lo de ser M2

[A401] Lo primero en que prueba vuesa merced A V ] quien G M2 M M1 S S1

[A402] que de una y otra suerte le conviene A V ] porque G M2 M M1 S S1

[A404] ora en la tusculana, ora en su heredad formiana (firmiana V) A V ] ora (àora

G) en su heredad formiana ora en la tusculana G M2 M M1 S S1

[A407] en la sierra, donde a pesar de los caniculares A V ] lugar donde G M2 M M1 S S1

\footnotetext{
$34 \quad$ Artigas Ferrando (1925: 403).

35 Artigas Ferrando (1925: 408).
} 


\subsection{El grupo $\gamma$ y los errores separativos de $\mathrm{G}$}

Los datos hasta aquí analizados nos llevan, de momento, a la delineación de un estema bipartido que representamos con este diagrama:

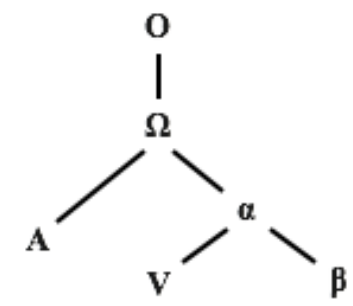

Ahora bien, dentro de la familia $\beta$, es necesario postular la existencia del grupo $\gamma$, del que forman parte los testimonios M, M1, M2, S y S1, los cuales comparten una única innovación monogenética que $\mathrm{G}$ no transmite, o sea, el error "metafóricas" en lugar de "metáforas":

[A428] «Illa veneranda -dice él de la virtud de la dicción- et omne prorsus plebeium excludens quae peregrinis utitur vocabulis. Peregrinum voco varietatem linguarum, translationem, extensionem, tum quodcumque a proprio alienum est». Y no hago diversa cabeza de esto último, porque, sin duda, las palabras peregrinas, las metáforas y los perífrasis son ajenos del propio y así los epiloga antes que diferencia.

metáforas A G ] methaphoricas M M1 S S1 metaphoricas M2 (V lagunoso)

El autor del Examen, valiéndose del magisterio de Aristóteles ${ }^{36}$, afirma que «la magnificencia de la elocución de tres cosas nace [...]: de variedad de lenguas, de translaciones, de extensiones». Para referirse nuevamente a estos recursos, parafraseando el texto de la Poética, en el fragmento en cuestión se utilizan tres sinónimos: "palabras peregrinas" (variedad de lenguas), "metáforas" (translaciones) y "perífrasis" (extensiones). La lección "metafóricas", resultado de la atracción del

36 Fernández de Córdoba cita la Poética aristotélica a través de la traducción de Alessandro Pazzi de' Medici publicada por primera vez en 1536 con el título Aristotelis poetica per Alexandrum Paccium, patritium fiorentinum in latinum conversa. La numeración de los capítulos adoptada por el abad de Rute e indicada en los marginalia invita a suponer que debió de manejar una edición posterior a la princeps ( $c f$. Elvira 2014, nota 77). Consultamos una edición de 1537 (Aristóteles, Aristotelis Poetica per Alexandrum Paccium, patricium Florentinum, in Latinum conuersa, Basileae: s.n., 1537, p. 48). 
sustantivo "palabras", difícilmente hubiera podido producirse en los cinco manuscritos de forma independiente.

Desde luego, la falta de otras corruptelas categóricamente monogenéticas, que puedan corroborar el subarquetipo $\gamma$, no permite descartar por completo la posibilidad de que los testimonios que nos ocupan desciendan directamente de $\beta$. Aun así, la presencia, en dichos manuscritos, de un par de deslices -si bien plausiblemente poligenéticos-, $\mathrm{y}$, sobre todo, su coincidencia en unos 17 casos de adiaforía $^{37}$, nos mueven a confirmar la existencia de $\gamma$, fundada en la corruptela "metafóricas". A continuación, reproducimos los otros dos errores localizados y una selección de las adiáforas aludidas:

[A406] que al fin supimos ser Teágenes y Cariclea G ] Clariquea A V Cariclia M M1 M2 S S1

[A430] «tollere humo, victorque virum volitare per ora» A G ] oras (corr. de hras S1) M M1 M2 S S1 (V lagunoso)

[A404] donde hay mucha que adonde hay poca gente A G V ] om. M M1 M2 S S1 [A417] el poema que con su gallarda imitación consiguiere este fin A G ] imitacion o invencion $\mathbf{M}$ imitazion ò invencion $\mathbf{M} 1$ imitaçio(n) e invençion $\mathbf{M} 2$ imitaçion e inbencion $\mathbf{S}$ imitacion e invencion $\mathbf{S 1}$ (V lagunoso)

[A420] quiero darle por postre otros A G ] quierole dar M M1 M2 S S1 (V lagunoso)

[A422] y el mismo, en los libros De natura deorum: «Nec consulto dicis occulte tamquam Heraclitus» A G ] de la naturaleza de los Dioses M M1 M2 de naturaleça de los Diosses $\mathbf{S}$ de naturaleza de los Dioses S1 (V lagunoso)

[A459] suspende un año la publicación de un soneto A G ] su M M1 M2 S S1 (V lagunoso)

Asumiendo, entonces, la descendencia común de M, M1, M2, S y S1 a partir de un único modelo, para excluir que dicha familia derive del testimonio $G$

37 De este cálculo, excluimos -es obvio- los numerosos loci en los que M2 coincide solo con M y M1, aunque no descartamos que la falta de correspondencia de S y S1 pueda depender de su contaminación con un ejemplar cercano a A (véase el apartado 2.7.). En la importancia que las variantes adiáforas pueden adquirir en tradiciones complejas, confirmando la hipótesis estemática trazada a partir de la localización de errores monogenéticos, insiste Paolo Trovato: «Even though the best manuals agree that only significant and non-polygenetic errors can be used as indicative errors, once a preliminary stemma has been sketched on the basis of indicative errors, lists of equally acceptable readings matching the distribution of indicative errors can provide a valuable control in complicated traditions. In Italian studies, these readings are often called lezioni caratteristiche [characteristic readings], i.e., readings which characterize, besides indicative errors, a group of witnesses; in this manual, I have opted for the non-literal but less ambiguous translation "confirmatory readings"》 (Trovato 2014: 116). 
es suficiente el hallazgo, dentro de este manuscrito, de al menos un error monogenético que no figure en $\gamma$. Entre las muchas corruptelas individuales de G, que implican la independencia de $\gamma$, seleccionamos solo una de las numerosas omisiones y algunas de sus innovaciones más significativas:

[A403] Y últimamente el mismo, Pro A. Caecina: «Aebutius iste, qui iam diu Caesenniae viduitate ac solitudine aleretur». Marco Celio a Cicerón: «Ut non modo mihi solus esse, sed Romae, te profecto, solitudo videatur facta».

Pro A. Caecina ... facta ] Aebutius ... aleretur A M M1 M2 S S1 ] Pro A. Caecina (Aebutius ... aleretur om.) M. Celio a Ciceron (Ut non modo ...facta om.) $\mathbf{G ~ o m}$. V

[404] Pero aún con menos embozo, en otro lugar poco delante del referido: «Maximamente ricordandomi in questa fervida adolescenzia de' piaceri della deliciosa patria tra queste solitudini di Arcadia». Y estaba, o se finge estar, entonces poblada y frecuentada por extremo de pastores y zagales y aun de villajes.

por extremo A M M1 M2 S S1 V ] por este modo G

$* * *$

[A408] Usen pues nuestros príncipes, mientras la alta paz de que goza España no les permite andar como a sus clarísimos mayores con lanza en cuja, ni hay gobiernos de reinos en que juntamente se ocupen todos.

en cuja A M M1 M2 ] en puño $\mathbf{G}$ en la mano $\mathbf{S}$ S1 enaja $\mathbf{V}$

Dejando a un lado las omisiones del primer fragmento, y deteniéndonos tan solo en los últimos dos pasajes, está claro que la lección "por este modo" en G es incorrecta, ya que la cita de Sannazaro, igual que las que la preceden, no justifica semejante lectura. Asimismo, la consulta del CORDE ha revelado la enorme frecuencia con la que la palabra "cuja", aderezo de la armadura de los soldados de la época, se solía asociar con la lanza. De hecho, se lee en Covarrubias: «Lanza en cuja y lanza en ristre son términos de la gente de armas». Por eso, hay que considerar la variante "en puño" una mera trivialización.

\subsection{M2 y los testimonios de $\delta$}

El grupo $\gamma$, cuya existencia acabamos de demostrar, parece dividirse en dos ramas distintas e independientes entre sí: la de M2 y la de $\delta$. Este ascendiente 
común de los manuscritos M, M1, S y S1 se prueba con facilidad apoyándonos en el error "no traigo diversa cabeza", en lugar del correcto "no hago diversa cabeza" 38 , y teniendo en cuenta las innovaciones que introduce en la transcripción de al menos un par de citas:

[A404-405] El Chiabrera en la canción que hizo a Colón: «Non perché umile in solitario lido / ti cingano, Savona, anguste mura»

ti cingano A G M2 ] Ti çingo M Ti cingo M1 S Te cingo S1 (V lagunoso) ${ }^{39}$

\begin{abstract}
$* * *$
[A407] Bajó el día siguiente a lo llano: allí sí que habría menester el pastor sombrerico para el sol, pues, aunque fuese el mes de marzo -que es la entrada de la primavera- decimos que aporrea el sol como mazo, y no era sino andada buena parte de abril, «en que el mentido robador de Europa / [...] en dehesas azules pace estrellas», ¿qué mucho, pues, sudasen los o las que hacían ejercicio, y más si era en campos tan calientes como los andaluces?
\end{abstract}

en dehesas azules A G M2 V ] en canpos de zaphiro M en campos de zaphiro M1 en campo de zaphiro $\mathbf{S}$ en campo de Zafiro $\mathbf{S 1}$

El verso que hoy se lee en las ediciones modernas de las Soledades reza: «en campos de zafiro pace estrellas». Jammes presenta tres versiones del mismo: la primitiva, «zafiros pisa, si no pace estrellas», comentada por Andrés Almansa y Mendoza en sus Advertencias; una versión intermedia, «en dehesas azules pace estrellas», puesta a caldo por Jáuregui en el Antídoto; y la definitiva «campos de zafiro ${ }^{40}$. Lo más probable es que el abad de Rute manejara una versión del poema correspondiente a la fase intermedia, aunque no podamos descartar que primara en este caso la necesidad de responder a Jáuregui, transcribiendo el verso tal y

\footnotetext{
38 El pasaje, ya referido en el apartado 2.2., es el siguiente: [A428] «Y no hago [hago A G M2 traigo M M1 traygo S S1 (V lagunoso)] diversa cabeza de esto último, porque, sin duda, las palabras peregrinas, las metáforas y los perífrasis son ajenos del propio y así los epiloga antes que diferencia». Según se infiere de la consulta del CORDE, ninguna de las dos fórmulas se registra en los documentos recogidos en el banco de datos. Por su parte, sin embargo, el Diccionario de Autoridades presenta solo la expresión "hacer cabeza", que «es lo mismo que hacerse fuerte». De ahí que consideremos correcta la lección de A, G y M2.

39 El verso que se lee en las ediciones consultadas del Chiabrera equivale al transcrito en A, G y M2. Además, aunque se considere la posible dialefa de "Savona anguste" en la lección transmitida en $\gamma$-"ti cingo, Savona, anguste mura"-, el verso seguiría sin observar la articulación rítmica del endecasílabo, fuera este a minore (acento en la cuarta sílaba) o a maiore (acento en la sexta sílaba).

40 Véase el estudio introductorio de Robert Jammes a su edición de las Soledades (Góngora 1994: 196-198).
} 
como el sevillano lo chancea en el Antídoto ${ }^{41}$. La lección "campos de zafiro", por consiguiente, sería una innovación de $\delta$, que demuestra, además, que nos las habemos con una tradición sumamente activa ${ }^{42}$.

La independencia de esta familia respecto a M2 resulta evidente a la luz de algunas corruptelas individuales de este testimonio, en su mayoría interpolaciones y omisiones:

[A412] $\mathrm{Al}$ que vemos enojado, ¿no decimos que está hecho un león? $\mathrm{Al}$ armado, ¿que lo está como un reloj? Luego, ¿aquel imita al león en todas sus acciones o este da horas, que es el oficio del reloj? Ni por imaginación, que la similitud solo consiste en las fierezas que hacen el hombre y el león enojados, y el armado en no faltarle pieza de las necesarias, como al reloj bien concertado, y otros símiles a este modo.

al reloj G M M1 S S1 ] el r. A a las armas del r. M2 (V lagunoso)

\begin{abstract}
$* * *$
[A420] Pues, quiero darle por postre otros que no solo por la calidad de su sangre generosa, sino por la de sus ingenios, pudieran darse muy por principio: el duque de Sesa, Gran Almirante de Nápoles; el duque de Feria
\end{abstract}

Gran ... Nápoles A G M M1 S S1 ] om. M2 (V lagunoso)

$* * *$

[A435-436] No se olvide otra vez, por mi amor, de cosa tan sabida como vulgar en nuestro idiotismo: "fulano tiene gruesa hacienda", "grueso caudal", "grueso trato". Y esto, no sin ejemplo de los antiguos, pues Plauto dijo: «Hem, a crasso infortunio», que con su beneplácito de vuestra merced romancearemos de «grande» y no de «gordo» infortunio.

antiguos A G M M1 S S1 ] latinos M2 (V lagunoso)

41 Para profundizar en el proceso de redacción de las Soledades, véase Góngora (1994: 14-21) y Roses Lozano (2007: 97-130).

42 «L'elemento determinante pare l'atteggiamento dello scriba rispetto al testo: nella tradizione quiescente il copista si sente in qualche modo estraneo al testo su cui lavora e ne ha rispetto; sbaglia, magari azzarda congetture, ma sempre al fine di un restauro conservativo. Nella tradizione attiva, invece, il copista ricrea il suo testo considerandolo attuale ed 'aperto', sicché -oltre a cadere nelle corruttele cui nessuno sfugge- opera interventi di un tipo alquanto diverso da quello consueto nella tradizione quiescente: soprattutto innovazioni che a suo parere incrementano il testo, ad es. rendendolo più piano e più 'contemporaneo', e che quindi non obbediscono ad intenti di restauro» (Vàrvaro 2006: 94). 


\begin{abstract}
$* * *$
[A451] Ríase vuestra merced en buen hora, que no faltará quien de vuestra merced se ría, conforme a aquello de matarás y matarte han, etc.

hora A G M M1 S S1 ] h. de nuestro Pöeta M2 (V lagunoso)
\end{abstract}

\title{
2.6. La constelación de $\delta$
}

Los errores separativos de $\mathrm{M}$ y los de $\mathrm{S}$, respectivamente conjuntivos entre M1 y S1, delatan la existencia, dentro de $\delta$, de dos ramas autónomas. En concreto, además de coincidir la segmentación del texto en 43 epígrafes, M y M1 comparten varias omisiones, interpolaciones y lecciones erróneas o características, entre las cuales destacan la omisión del mismo título de la obra y otras innovaciones igualmente relevantes:

[A401] Pero en todo acontecimiento, pues a vuestra merced le consta que nuestro autor es poeta y debe constarle que este nombre -según buenos autores- se derivó de $\pi$ oté $\omega$ (que significa formar y fingir), de donde también se dijo figulus el ollero o alfaharero -que tal parentesco tienen ambos ejercicios-, déjele hacer, que él sabrá acomodarse a la ocasión y necesidad, a fuer de buen ollero...

ollero A G M2 S S1 V ] caballero M M1

[A414] Quien dijese que con la espada y lanza, invención de los Lacedemonios según Plinio- o con el arco y flechas, invención de los Scitas o de Perses o Apolo, hizo tal capitán esta o aquella hazaña, ¿diría mal? ¿o entenderíamos que con las mismas -numero: espada y lanza de los Lacedemonios, o con el arco y flechas de los referidos inventores- las hizo? No, por cierto.

o con el arco ... las hizo A G M2 S S1 ] om. M M1 (V lagunoso)

[A424] Y dejando de tratar de Petronio Árbitro y Apuleyo, que por la extravagancia de palabras han dado tanto que hacer a sus intérpretes, $\mathbf{y}$, asimismo, del Dante entre los vulgares toscanos - cuya varia musa con misteriosos pensamientos se subió ya tal vez cual otro Astolfo a lo más alto de su Paraíso...

y, asimismo ... toscanos A G M2 S S1 ] om. M M1 (V lagunoso) 
Particularmente significativa se antoja la siguiente corruptela:

[4A43] Siendo así que lo común es en los nombres que referimos servir la $u$ y la $i$ de consonantes verdaderamente y haberlas proferido por tales aquellos mismos que, cuando les tornó más a cuento, las pronunciaron vocales, ora sea en el principio, ora en el fin del verso, que esto verá vuestra merced cuán poco importe.

tornó G M2 S S1 ] torna A estubo M M1 (V lagunoso)

El CORDE documenta la mayor frecuencia de la expresión "estar a cuento" (20 casos en 16 documentos entre 1550 y 1699) frente a "tornar a cuento". Por su parte, el Diccionario de Autoridades registra solo el modo adverbial "a cuento" y la construcción más habitual "venir a cuento". Sin embargo, el hecho de que esta fórmula aparezca también en otra obra del abad de Rute, la Historia y descripción de la antigüedad y descendencia de la Casa de Córdoba, delata su cristalización en el usus scribendi de su autor. Por ello, la lección de M y M1 debe considerarse una trivialización.

También en el caso de los manuscritos S y S1 asoma cierto grado de parentesco, muy evidente ya desde el principio y, en particular, a partir de la errónea atribución del Examen a Francisco de Amaya ${ }^{43}$.

Seleccionamos unas cuantas corruptelas conjuntivas de S y S1 -y separativas con respecto a M y M1-, no menos relevantes:

[A408] Usen pues nuestros príncipes, mientras la alta paz de que goza España no les permite andar como a sus clarísimos mayores con lanza en cuja, ni hay gobiernos de reinos en que juntamente se ocupen todos.

43 Dicha atribución puede explicarse por la difusión en Salamanca de un ejemplar del Antídoto comentado por el jurisconsulto antequerano y de una «docta defensa» del propio Amaya, citada por Salcedo Coronel en su comentario a la obra de Góngora (José García de Salcedo Coronel, Segundo tomo de las obras de Don Luis de Góngora..., Madrid, Imprenta de Diego Díaz de la Carrera, 1644, pp. 617-618), que debieron de inducir a error a los copistas salmantinos. A este propósito, resulta particularmente interesante el examen que hizo Jammes (1962: 193-215) de las glosas de Amaya al Antídoto, pues revela la ausencia de rasgos comunes entre estas y el Examen: «Le manuscrit 2006 de la Bibliothèque universitaire de Salamanque (voir plus loin la description sommaire de ce manuscrit) l'attribue à Francisco de Amaya, en se fondant sur une remarque de Salcedo Coronel dans son commentaire aux sonnets CXL et CXLI (Segundo* tomo de las obras de Don Luis de Góngora comentadas... , p. 617 et 620). Même attribution à Amaya dans le manuscrit 2123 de la même bibliothèque (ex 833 du Palais- Royal), qui n'est qu'une copie tardive du précédent. L'attribution à Amaya manque de fondement, car Salcedo se borne à dire qu'il écrivit une "docta defensa...contra el Antídoto", sans donner d'autre précision. Si Francisco de Amaya était l'auteur de l'Examen del Antídoto, on devrait s'en apercevoir en comparant ce traité aux notes marginales de Francisco de Amaya, que je publie à la fin de cet article: or il n'y a pratiquement aucun trait commun entre les deux» (Jammes 1962: 194, nota 4). 
en cuja A M M1 M2 ] en puño $\mathbf{G}$ en la mano $\mathbf{S} \mathbf{S 1}$ enaja $\mathbf{V}^{44}$

[A424] Pues, ¿qué se le siguió al poeta de este trueco de estilo en los poemas referidos? Que dijese de ellos Daniel Bárbaro, hombre acreditadísimo en su tiempo con los profesores de buenas letras que «per lo artificio delle allegorie e degli enigmi mirabili appariscono a chi gli legge».

profesores A G M M1 M2 ] profetas S prophetas S1 (V lagunoso)

$* * *$

[A450] Y si quiso advertir nuestro autor de las Soledades que no era dura, hizo bien y a modo de poeta, pues a los tales se permite usar de aposiciones o epítetos tan sabidos como este.

sabidos A G M M1 M2 ] salados S S1 (V lagunoso)

La lección "profetas” de S y S1, en el penúltimo fragmento, se explica como la fallida exégesis de una abreviatura de la palabra "profesores" en el modelo copiado. De la misma manera, la lección "salados", en el último párrafo, es resultado de la lectura errónea de los grafemas que componen la segunda sílaba de "sabidos". El adjetivo "salados" 45 , por otra parte, no vendría al caso.

Corroboran la relación de parentesco entre S y S1 numerosos errores supuestamente poligenéticos, entre los cuales destacan nueve casos de omisión por homoioteleuton $^{46}$ :

44 Considérese lo que se ha dicho a propósito de este mismo fragmento en el análisis de los errores separativos de G (apartado 2.2.).

45 «Gracioso, agudo, o chistoso: como es hombre salado, o conversación salada» (Aut.).

46 Por lo que atañe al posible origen monogenético de los saltos ópticos, resultan particularmente significativas las palabras de Montanari: «È quindi agevole determinare, all'interno dell'opera considerata, quanti siano i luoghi che presentano un piège à copiste assimilabile a quello che vede la coincidenza in omissione, e calcolare il rapporto numerico fra le situazioni in cui la trappola è scattata e quelle che hanno invece visto un'esemplazione fedele. [...] Nel caso dunque si diano numerose situazioni identicamente propizie al salto da pari a pari, e solo in una si sia verificata corrispondenza nell'incidente, si potrà valutare non poligenetico, e dunque congiuntivo, l'errore, con quanta maggiore probabilità per quanto minore sia il grado di corrispondenza fra $i$ due segmenti che avrebbero innescato l'errore. (Troppo spesso viene negata la congiuntività di un'omissione per la possibilità di un salto da pari a pari motivato da una corrispondenza debole, e unico a fronte di un notevole numero di situazioni perfettamente identiche, che non hanno dato luogo ad omissione, anche se certo la poligenesi "teoricamente ... non si può escludere")» (Montanari 2003: 312). A este propósito, también cabe mencionar una nota de Baldissera y Bonilla Cerezo a su traducción de Maas: «la experiencia ecdótica enseña que la caída por "salto de igual a igual" no siempre es poligenética según podría parecer: la probabilidad de que dos o

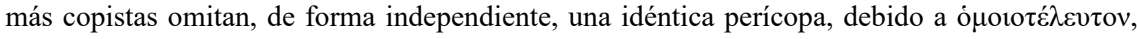


[A401] también se dijo figulus el ollero o alfaharero [...] a fuer de buen ollero A G M M1 M2 V ] om. S S1

[410] los maestros llaman "cacophaton" -según quieren Quintiliano y Diomedes-, o cacephaton -según Sosípatro Carisio-, y vulgarmente "cacofonía" A G M M1 M2 ] om. S S1 (V lagunoso)

[A417] y objeto adecuado ayudar deleitando -siendo el blanco (aunque inadecuado) arquitectónico y principal ayudar A G M M1 M2 ] om. S S1 (V lagunoso) [A423] Escribió en verso heroico el Hesíodo y la Mopsopia en que describió oráculos de mil años venideros A G M M1 M2 ] om. S S1 (V lagunoso)

[A441] Alguno de los demás dice que la sinalefa se llama sinéresis, pero ninguno que la sinalefa se comete en medio de la dicción A G M M1 M2 ] om. S S1 (V lagunoso)

[A451] sin ser gordos, son de gran cuerpo. Como también advertirá que "adusto", cuando se refiere al cuerpo y no al color A G M M1 M2 ] om. S S1 (V lagunoso)

[A451] «[...] se mira en su original». Yo al menos por tal le tengo en materia de poema nupcial y considerándolo en su original, como vuesa merced nos manda A G M M1 M2 ] om. S S1 (V lagunoso)

[A461] El istmo se entiende [...] en su fantasía traslada los Lestrigones y los istmos al estrecho de tierra que divide la nueva España del Perú A G M M1 M2 ] om. S S1 (V lagunoso)

[A465] «Por cuyo perífrasis - dice- nadie entenderá hijo, ni debe entenderlo. Mírese lo que digo». De que nadie entenderá hijo, mucho se promete vuesa merced, pero a la proposición de que ni debe entenderlo, digo, mi señor, que distingo A G M M1 M2 ] om. S S1 (V lagunoso)

\subsubsection{M1 descriptus de M}

En sentido lato, la conditio sine qua non para que un códice pueda definirse como descriptus es que presente todos los errores de su modelo, más al menos un error propio ${ }^{47}$. En este sentido, considerando, por un lado, la completa

depende obviamente de la conformación gráfico-morfológica del pasaje, que puede ocasionar saltos (muchas o pocas palabras / terminaciones con grafías semejantes o idénticas). De ahí que algunos homoioteleuta puedan tener valor también conjuntivo» (Maas 2012: 75, nota 55). En este mismo aspecto insiste más recientemente Tanganelli: «En efecto, siempre hay que tener muy en cuenta una simple regla: la probabilidad de coincidencia poligenética disminuye cuanto mayor es el número de casos en los que un mismo grupo de testimonios presenta los mismos saltos de igual a igual (con independencia de que dichas lagunas sean de veras accidentales o reflejen más bien, como en ocasiones sucede, unas omisiones conscientes del copista). Por este motivo, el estudio de dichas lagunas puede considerarse, al menos en los textos en prosa de cierta extensión, una especie de 'prueba del nueve' para confirmar las familias establecidas a través de los errores significativos (es decir, mediante corrupciones seguramente monogenéticas)» (Tanganelli 2016: 215-216).

47 «Si un testimonio $J$ muestra todos los errores de otro conservado, $F$, y además al menos uno 
coincidencia de errores entre M y M1 y, por otro, tanto la falta de corrupciones que separen el primer testimonio del segundo como la presencia de lecciones erróneas propias solo de M1, cabe postular que este apógrafo sea una copia de M. Valgan como ejemplo la lectura errónea del grupo consonántico st por $b l$ en la palabra "pueblos" y algunas de las omisiones más significativas de M1:

[A408-409] ¿Qué quisiera vuestra merced? Que cuando el duque estuviera más ocupado en cosas de sus pueblos o casa, o en un capítulo o asamblea de su Orden del Tusón, ¿se le pidiera que lo dejara todo y escuchara las Soledades...

pueblos A G M M2 S S1 V ] puestos M1

$* * *$

[A414] De suerte que si Plinio, en el capítulo 56 del séptimo libro de su Natural Historia, si Clemente Alejándrino en el primer libro de sus Stromas, si Polidoro Virgilio en los De inventoribus rerum, no hicieron mención del inventor de alguna cosa, ¿por eso no lo pudo ser fulano? ¿O la tal cosa fue congénita con el mundo? ¡Bravo abreviar la diligencia, la memoria o el ingenio de los demás!

mención A G M M2 S S1 ] om. M1 (V lagunoso)

$* * *$

[A426] Y Cicerón había dicho primero: «Hoc ego philosophi non arbitror testibus uti, qui aut casu veri, aut malitia falsi, fictique esse possunt, argumentis et rationibus oportet quare quidque ita sit docere».

philosophi ... veri A G M M2 S S1 ] om. M1 (V lagunoso)

\subsubsection{S1 descriptus de $\mathrm{S}$}

Las consideraciones y premisas que se han tenido en cuenta en el caso de $\mathrm{M}$ y M1 nos ayudan a determinar la relación que une S1 con el testimonio S: el primero de ellos, además de compartir todos -0 casi $^{48}$ - los errores del segundo, presenta algunas corruptelas propias y varias lecciones características:

proprio, en tal caso $J$ debe derivar de $F$ » (Maas 2012: 31).

48 El amanuense de $\mathrm{S} 1$, en varias ocasiones, intenta corregir ope ingenii los errores evidentes de su modelo, si bien con escasa fortuna: a) [A429] «Doctrina por cierto puesta en razón, porque si de lo admirativo nace lo risible [noble A risible G M M1 M2 pusible $S$ plausible $\mathbf{S 1}$ (V lagunoso)], también nacerá lo deleitable»; b) [A443] «lo común es, en los nombres que referimos, servir [servir A G M M1 M2 reuir S recivir S1 (V lagunoso)] la $u$ y la $i$ de consonantes verdaderamente». Desde luego, no debe extrañarnos que un codex descriptus pueda presentar 
[A414] Como pudo Virgilio hacer a Alcimedón excelente artífice de pastoral vajilla, ¿no podrá nuestro poeta hacerle inventor de alguna suerte de cucharas de las muchas que, para usos diversos, ha inventado la rústica agudeza?

vajilla A G M M1 M2 S ] vasija S1 (V lagunoso)

[A419] Que no fue arrogancia la de aquel excelente músico Antigénidas, sino justo aprecio de su ciencia y de la ignorancia del pueblo, cuando, aprobando este poco a un su discípulo que tañía muy conforme a las reglas de aquel arte, levantando la voz, el maestro le dijo en presencia de todos: «Mihi cane et Musis».

aprobando A G M M1 M2 S ] aprovechando S1 (V lagunoso)

[A434] Cuando dice nuestro poeta «Cabo lo hizo de esperanza buena», pone vuestra merced por parergo agudeza extraordinaria: «No sería tan malo llamarlo Cabo de Buena Esperanza». Pero la musa se ha dejado decir que en servicio de sus endecasílabos no lo recibiría por barrendero.

\section{barrendero A G M M1 M2 S ] verdadero S1 (V lagunoso)}

Notable es también otro caso que despeja cualquier duda sobre la descendencia de $\mathrm{S} 1$ con respecto a $\mathrm{S}$ :

[A425] Según Aristóteles las artes, en cuanto a su esencia y a su objeto, inmudables son y eternas; pero no en cuanto al modo de enseñarlas o aprenderlas, que este admite variedad según los tiempos e ingenios, con los cuales de ordinario prevalece la novedad, como cosa que aplace.

a su esencia y a su objeto A G M2 M M1 ] a su essencia y a su ob reato $\mathbf{S}$ a su essencia (y a su om.) ornato S1 (V lagunoso)

eternas A G M2 M M1 S ] ciertas S1 (V lagunoso)

correcciones o tentativas de enmienda relativas a las innovaciones más o menos visibles de su modelo. De hecho, si -como advierte Tanganelli- «no es acertado definir un codex descriptus como un testimonio conservado que presenta todas las innovaciones de otro igualmente conservado, más al menos una innovación propia, porque el copista de un descriptus puede y suele subsanar los pequeños deslices de su modelo» (Tanganelli 2016: 197), dada la flagrancia de algunos errores de S, ciertas correcciones de S1 son perfectamente admisibles. 
Para comprender lo que debe de haber ocurrido en S1, reproducimos el pasaje del manuscrito $\mathrm{S}$ :

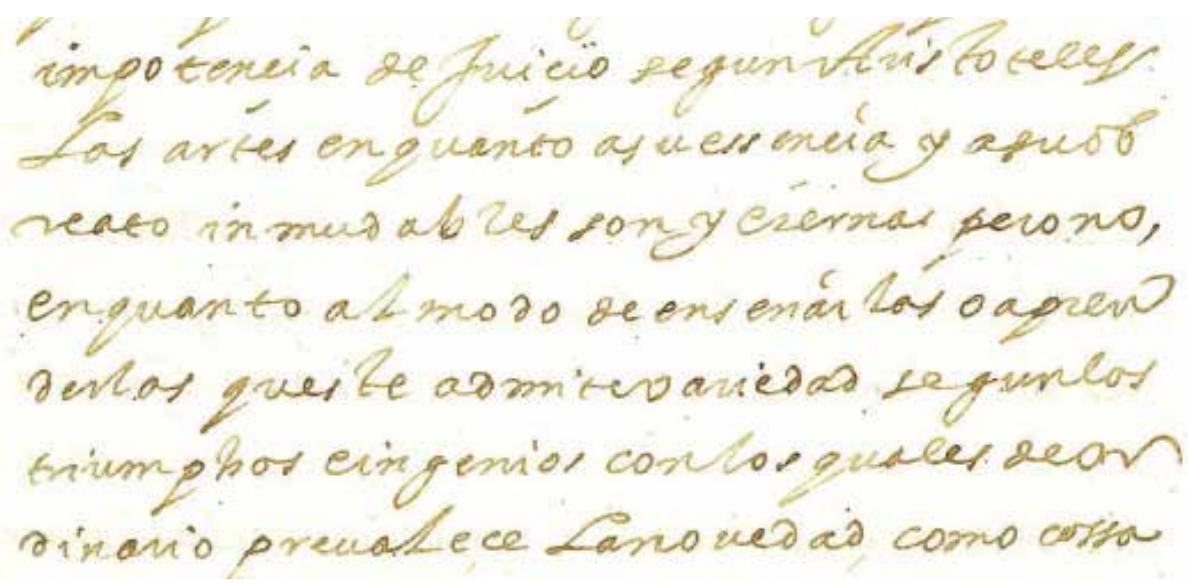

En la segunda y la tercera línea, leemos: "las artes en quanto a su essençia y a su ob / reato inmudables son y eternas". La lección "ob reato", quizá resultado de la transmisión poco legible de la palabra "objecto" en su modelo, es un error flagrante de S que el copista de S1 debió intentar enmendar ope ingenii con "ornato" y la omisión de "y a su". En cuanto a la innovación "ciertas", en lugar de "eternas", hay que considerar en S el extraño ductus de las letras et y su cercanía a la cedilla de la palabra "essençia" en la línea superior: esto evidentemente propició el error del copista de S1, el cual, por leer $c i$ en vez de et ("ciernas"), decidió corregir con "ciertas".

\subsection{La contaminación de S y S1}

La presencia de curiosas coincidencias textuales entre A y S nos obliga a barajar la posibilidad de que el amanuense del testimonio salmantino (o el de su modelo) tuviese acceso a dos manuscritos diferentes: $\delta$ u otro apógrafo suyo, por un lado; un ejemplar cercano a A, por otro. En consecuencia, se habría producido una contaminación tanto de ejemplares como de lecciones ${ }^{49}$.

49 «2. La contaminación de ejemplares no puede ser analizada del mismo modo que las demás y, por tanto, no atañe a nuestro discurso: cuando un copista, o para completar un ejemplar incompleto, o porque ha encontrado un ejemplar más fácil de leer o con más autoridad, transcribe alternativamente a partir de dos ejemplares, su copia pertenece, alternativamente, solo a uno de los grupos de procedencia de los dos ejemplares. 3. La contaminación de lecciones es la consecuencia de un cotejo realizado en el testimonio del que haya derivado el códice. Esta contaminación se puede 
La primera afectaría a una porción relativamente reducida del texto ${ }^{50}$ y se podría demostrar a través de una sucesión de variantes adiáforas y, sobre todo, de verdaderos errores comunes a los dos modelos:

[A412] lo muestra la experiencia misma, y hablando ella, callarán los escritores $\mathbf{G}$ M M1 M2 ] om. A S S1 (V lagunoso)

[A412] está lleno de vino como suelen los cueros G M M2 ] lo suelen estar A S S1 osuelen M1 (V lagunoso)

[A413] tendría la cucharita sus mil y quinientos años G M M1 M2 ] seis A S S1 (V lagunoso)

[A414] Topa vuestra merced con aquellos versos G M M1 M2 ] en A S S1 (V lagunoso)

[A417] eso es ya dar indicio claro de que «sincerum est nisi vas [...]» G M M1 M2 ] om. A S S1 (V lagunoso)

La segunda, en cambio, quedaría patente en el resto de la apología, manifestándose por medio de innovaciones aisladas comunes a $\mathrm{A}$ y S. Seleccionamos los casos en los que el origen poligenético, aunque factible, es más difícil de suponer:

[A421] «Fannius Hermogenis laedat conviva Tigelli?» G M M1 M2 ] convivia A S S1 (V lagunoso)

[A436] ¿Y Horacio: «multa merces, multa prece, multa aura, multa tellure... G M M1 M2 ] aurea A S S1 (V lagunoso)

[A449] como si sobre los hombros de cada cual se hubiera dejado caer un sino celeste G M M1 M2 ] signo A S S1 (V lagunoso) ${ }^{51}$

[A461] en las comparaciones no se requiere omnímoda verdad, ni semejanza: sobra que combinen en algún principal atributo G M2 ] convengan A S S1 convienen M M1 (V lagunoso)

[A462] «Alius namque ibi isthmos angustia simili est [...]» G M M1 M2 ] isthmus A S S1 (V lagunoso)

clasificar, según sus modalidades, como: a) contaminación simple (fruto de un único cotejo con un único ejemplar); b) contaminación fraccionada (resultado de varios cotejos sucesivos con un único ejemplar); y c) contaminación múltiple (a partir de una serie de cotejos con más de un ejemplar), que también puede ser fraccionada. En virtud del mayor o menor grado de intensidad del cotejo también se podrían distinguir tres clases: a) contaminación esporádica (las lecciones extraídas del segundo ejemplar son ocasionales y aisladas); b) contaminación densa (las lecciones se cifran no solo en palabras aisladas, sino en grupos de palabras u oraciones, a menudo introducidas en el primer ejemplar); c) contaminación completa (se da cuando el que realiza el cotejo quiso reproducir todas las diferencias entre sus dos ejemplares)» (Segre 2016: 9-10).

50 La porción de texto a la que aludimos coincidiría aproximadamente con las páginas 412-418 de la transcripción de Artigas Ferrando (1925).

51 Aunque ambas lecciones, "signo" y "sino", encajan en el fragmento citado, el hecho de que el abad de Rute esté replicando a Jáuregui acerca del uso repetido de la adversativa nos lleva a suponer que en el original figurara "sino", y que la variante "signo" sea una banalización del amanuense de A (o de un testimonio cercano) transmitida a S. 
Destacan también un par de casos donde $\mathrm{S}$, o su ascendiente, debieron de acudir a los dos testimonios a su alcance, cotejándolos y dando lugar a variantes "híbridas", fruto de la combinación de las lecciones transmitidas por cada uno de los modelos:

[A433] Usole Lucano: «Iam tumuli collesque latent, iam flumina cuncta / condidit una palus vastaque rígido mersit, / absorpsit penitus rupes».

Usole G M M2 ] (Usole om.) i tambien A Usolo M1 Usso (Ussò S1) tambien S S1 (V lagunoso)

[A436] Luego no habló, ni aun imitó mal nuestro autor de las Soledades.

Autor de las Soledades G M M1 M2 ] poeta (de las Soledades om.) A poeta (poetta S1) de las Soledades S S1 (V lagunoso)

En ambos casos, el copista del manuscrito contaminado, hallándose ante dos lecciones distintas, debió de innovar, dando entrada, así, a una tercera variante, partícipe a su vez de las dos que figuraban en los manuscritos cotejados; luego las lecciones "usso tambien" y "poeta de las Soledades" de S derivarían de la combinación de "usole" de $\alpha$ con "i tambien" de A, por un lado, y de "autor de las Soledades" $(\alpha)$ con "poeta" (A), por otro.

Por supuesto, es difícil encontrar evidencias textuales que delaten el testimonio en el que se ha producido la contaminación: este podría ser el mismo $\mathrm{S}$, o un interpositus entre dicho apógrafo y $\gamma$. Empero, sin descartar ninguna hipótesis, transcribimos un fragmento que quizá pueda arrojar un poco de luz al respecto:

[A407] La acción que aquí se describe fue, sin duda, en la primavera, pero distingue tempora et concordabis iura. Cuando llegó el peregrino a la montaña donde estaban los cabreros, era de noche: pues noches de primavera sub dio, sub Iove frígido.

La acción ... rígido A G $\mathbf{M} 2 \mathbf{V}$ ] La accion que aqui se descrive fue sin duda en la Primavera (pero ... primavera $o m$.) sub Dio, sub Jove frigido M M1 La acçion $<$ pero distingue tempora et concordabis iura cuando llegò el peregrino a la monttaña donde estavan los cabreros era de noche, pues noches de primavera sub Dio, sub Jove frigido etc(étera) $>$ (marg.) que aqui se describe fue sin duda en la primera (u?)rca sub Dio sub Jove frigido $\mathbf{S}$ La accion pero, distingue tempora et concordabis iura; quando llegò el peregrino a la monttaña donde esttaban los cabreros era de noche, pues noches de primavera sub dio, sub Jove etc(étera). La accion digo, que aqui se descubre fue sin duda en la primera cerca sub Dio sub Jove frigido S1 
Nos encontramos ante un salto de igual a igual presente en $\mathrm{M}$-cabe conjeturarlo asimismo ya en $\delta-$ y corregido en el margen por el copista de $\mathrm{S}$. Aunque las omisiones ex homoioteleuton pueden ser poligenéticas y asomar en dos manuscritos de manera independiente, nos parece más probable que dicha corrupción se deba al copista de $\delta$ y que el amanuense de S, percatándose del error, lo haya corregido ope codicum acudiendo al ms. A o a otro testimonio colateral de este. Admitiendo esta eventualidad, tendríamos que remontar el origen de la contaminación al propio $\mathrm{S}$.

Sea como fuere, sin ninguna intención de decantarnos por una u otra solución, proponemos el siguiente estema:

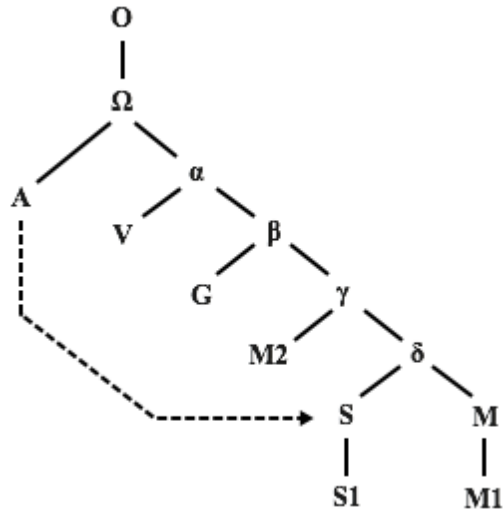

\subsection{López Viñuela y las supuestas variantes de autor}

En un estudio de $1998^{52}$, a partir de algunas discrepancias textuales entre el ms. 3906 de la Biblioteca Nacional (nuestro A) y los demás testimonios del Examen, Ana Cristina López Viñuela defendió la hipótesis de la supervivencia de dos versiones del texto del abad de Rute. Se trataría, según afirma la estudiosa, de un original primigenio, por un lado, y de una versión enriquecida con correcciones de puño y letra del autor, por otro. López Viñuela fundó su propuesta exegética sobre algunas cartas que Fernández de Córdoba envió a su amigo Díaz de Rivas, luego publicadas por Dámaso Alonso ${ }^{53}$, que nos proporcionan en efecto muchas noticias acerca tanto de la divulgación como de la inmediata recepción del Examen entre los eruditos de la época.

52 López Viñuela (1998: 377-388).

53 Alonso (1975: 27-58). 
Las que merecen mayor atención son tres y están fechadas, respectivamente, en Granada, el 25 de julio de 1617; en Rute, el 29 de junio de 1620; y, finalmente, de nuevo en Rute, el 7 de julio del mismo año. En la misiva granadina se lee:

La respuesta del Antídoto voy trasladando. Fáltame poco, y espéranla muchos en este lugar, que an tenido noticia della y alguna esperanza de mi pluma. Nadie la a visto fuera de Juan de Villegas, el Governador de Luque, a quien leí un pedazo, y el Doctor Andrés del Pozo y Áuila, cura de la Ventosa, que açertó a estar aquí, hombre muy versado en letras humanas y gran Poeta, amigo antiguo mío, de Granada y Roma. Y aunque no tenía en muy buen concepto el modo de componer moderno de nuestro Don Luys, le formó mejor después de oída mi defensa. En acabando de trasladarla yo, se hará otros traslados y partiçiparán della los amigos, que los muchos que ay en este lugar legos no me dan lugar a darme de todo punto a las letras y a los que tratan dellas [...]. (Alonso 1975: 35)

La «respuesta» aludida sería precisamente el Examen, del cual se afirma que se sacarán varias copias para que lo puedan disfrutar otros doctos lectores, además de Andrés del Pozo y Ávila, con quien el abad de Rute debió de coincidir durante su estadía en Granada.

La segunda carta, la de junio de 1620, nos brinda datos más útiles:

La defensa de Don Luys me pide también de Madrid con gran instancia el licenciado Francisco Martínez, porque por averla loado Lope de Vega y otros hombres entendidos, la desean los demás. Y como no tengo sino el original, no me atreuo a sacarla de mi poder; con todo, si V. M. puede haçer sacar della un traslado para V. M. y otro para mí, se la remitiré y satisfaremos a los deseos de Madrid y Sevilla. (Alonso 1975: 42)

Naturalmente, Fernández de Córdoba se niega a remitir el original del Examen para no desprenderse del único ejemplar de su obra: de ahí que le pida a Díaz de Rivas que haga sacar un par de copias para satisfacer las peticiones que le llegaban desde Madrid y Sevilla ${ }^{54}$.

La sucesiva epístola de julio, escrita apenas veinte días más tarde, ratifica que el original no viajó nunca a Córdoba, y curiosamente en ella se menciona tan solo el traslado con rumbo a Madrid, que fue a parar algo después a las manos de Francisco Martínez Portichuelo ${ }^{55}$ :

54 Tanto Dámaso Alonso (1975: 27-58) como López Viñuela (1998: 377-388) infieren de esta misiva que Fernández de Córdoba estaría dispuesto a arriesgarse a enviar el original a Díaz de Rivas para que sacara dos copias del Examen. Lo que nos parece más probable es que el abad de Rute simplemente le pida al amigo cordobés que se haga cargo de los traslados aludidos.

55 Según se desprende de la séptima carta del epistolario, fechada en Rute el 28 de septiembre de 1620: «...y estoy no poco contento de auer concluydo y remitido al Licenciado Francisco Martínez mi defensa de las Soledades, por salir de todo punto de estas materias, puesto que las 
Verá Vuestra Merced lo que le quiero, pues estando en víspera de un disanto que yo no querría que llegase, que es ver lo que a escrito contra mi apología Don Juan de Jáurigui, aunque otros dizen no a escrito nada, y aviendo de valerme de Scalíjero, se le remito en esta duda. V. M. le vea, y la apología de Don Lorenzo Ramírez contra Radero, y me las buelua luego por sí o por no; y lo mesmo haré de los demás libros que V. M. uviere menester. La defensa de las Soledades no puede yr porque se está trasladando para Madrid, de donde me sacan la vida, que el original bien ve V. M. que no es bien fiarle de caminos, y que se me pierda con lo demás que anda con él. (Alonso 1975: 48)

Dicho epistolario certifica, en consecuencia, que el abad de Rute, entre 1617 y 1620, difundió una serie de copias de su apología en distintos momentos, todas ellas sacadas, al parecer, a partir de un mismo original. A la luz de estos datos, López Viñuela imagina que el autor pudiera aportar cuando menos algunas pequeñas correcciones a dicho original entre un traslado y el sucesivo.

Si aceptáramos sus conjeturas, deberíamos optar por otra hipótesis estemática que contemplaría la descendencia del manuscrito A de una versión retocada del original:

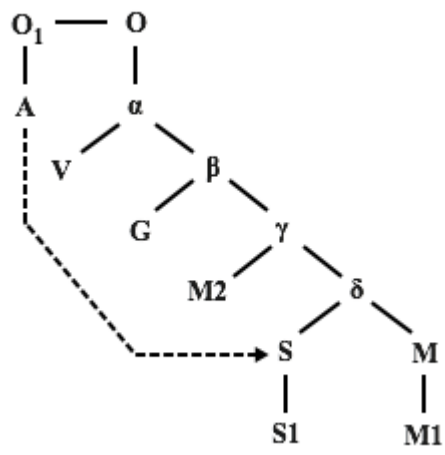

Ahora bien, de entre los numerosos loci critici seleccionados por López Viñuela, solo por lo que respecta a dos variantes del testimonio A se podría postular, en una primera ojeada, su atribución al mismo autor ${ }^{56}$ :

confieso por muy gustosas, como curiosas para quien no tiene otras a que atender más preçisas, como yo» (Alonso 1975: 55). Acerca de la participación de Francisco Martínez de Portichuelo en la polémica gongorina, véase Roses Lozano (2007: 189-194).

56 El resto de las lecciones en las que López Viñuela se apoya para demostrar la existencia de una segunda redacción del Examen coinciden, grosso modo, con las que analizamos en los apartados 2.2. y 2.3., que, a nuestro juicio, no implican necesariamente una intervención del autor. En los casos que hemos seleccionado, como se ha visto, es más lógico y económico suponer, en 
[A436] Prosigue vuestra merced culpando en nuestro poeta la siguiente frasis: «Que a mucha fresca rosa»; «Tanto garzón robusto, / tanta ofrecen los álamos zagala»; «tanta náutica doctrina»; «besó ya tanto leño».

álamos A ] arboles G M M1 M2 S S1 (V lagunoso)

$* * *$

[A409] Pues, y a aquellos versitos del cabrero, «que a rüinas y estragos / sabe el tiempo hacer verdes halagos», ¿qué les halla vuestra merced de malo?

sabe el tiempo A ] suele el t. G M M1 M2 el t. suele $\mathbf{S}$ el t(iem)po suele S1 (V lagunoso)

En el primer fragmento, se podría imaginar que el abad de Rute, tras citar en su comentario el v. 664 tal como aparecía -según nos informa Jammes ${ }^{57}$ - en la primitiva redacción de la Soledad primera («tanta ofrecen los árboles zagala»), al darse cuenta más tarde del retoque introducido por Góngora (la sustitución de «árboles» con «álamos»), volvió sobre el texto del Examen al objeto de modernizar el endecasílabo con la lección que se lee en A.

Por lo que se refiere al cambio de la lección "suele" de $\beta$ por "sabe" en A, podría razonarse de la misma forma. La única diferencia, en este caso, radicaría en que "suele" no se registra en ninguna fase redaccional del poema gongorino, siendo en cambio el fruto de un error cometido por Jáuregui en el Antídoto: error que Fernández de Córdoba habría reconocido y corregido solo en un segundo momento, durante la revisión de su defensa.

A estos casos, cabría añadir una tercera lección de A, no mencionada por López Viñuela, para la cual igualmente podría barajarse la idea de una intervención tardía del autor:

[A419] En Madrid, emporio de todos los buenos ingenios y estudios del mundo, como corte al fin del mayor monarca que en él ha habido, Pedro de Valencia, cuya aprobación sobrará para cosas mayores, don Lorenzo Ramírez de Prado del Consejo Real, el padre fray Hortensio Félix Paravicino, predicador de Su Majestad, Luis de Cabrera de Córdoba, Manuel Ponce; en Salamanca, toda ella y el maestro Céspedes, que ya pasó a mejor vida...

el padre ... Paravicino A ] el maestro fray Hortensio (Félix om.) Paravicino (Palavicino G S S1) G M M1 S S1 el maestro fray Hortensio (Félix om.) Palaviçino

\footnotetext{
ausencia de datos ciertos, que las discrepancias entre A y la rama de $\alpha$ son el resultado de errores cometidos en este subarquetipo y en su apógrafo $\beta$.

57 Véase Góngora (1994: 326-327).
}

Edad de Oro, XXXVI (2017), pp. 191-232, ISSN: 0212-0429 
$<$ Luis Tribaldos de Toledo chronista de su M(ajestad) / don Iñigo Aguirre caballero del habito de $\mathrm{S}$ (antiago) $>$ (marg.) M2 (V lagunoso)

predicador de Su Majestad A ] om. G M M1 M2 S S1 (V lagunoso)

Sin detenernos en cuestiones ancilares, como la sustitución por atracción del sustantivo "padre" por "maestro", o la oscilación gráfica "Paravicino" / "Palavicino", común en la época, lo que de veras importa es la presencia, en dicho testimonio, de la lección "predicador de Su Majestad", título que el trinitario madrileño lució solo a partir de diciembre de $1617^{58}$, cinco meses después de esa primera misiva granadina en la que el abad informaba a Díaz de Rivas acerca de la reciente conclusión de su apología.

La hipótesis de un original revisado, del cual derivaría A, presenta no pocos puntos débiles. De hecho, hay al menos dos razones fundamentales que nos obligan a rehusarla. En primer lugar, López Viñuela no considera en ningún momento la cuestión del arquetipo, infringiendo así una sencilla regla ecdótica: para demostrar la presencia de un original en movimiento -0 , cuando menos, la pervivencia de variantes de autor en la tradición conservada- es necesario, a falta de autógrafos, hallar evidencias textuales categóricas; es decir, debe resultar indemostrable la existencia de un arquetipo. En cambio, como ya se ha comprobado, en el caso del Examen contamos con elementos válidos para suponer la descendencia común de todos los testimonios a partir de un mismo apógrafo $\Omega$.

El segundo límite estriba en que López Viñuela infravalora también otro aspecto histórico, quizá el más relevante de los que se extraen de las cartas del abad de Rute. A saber: el contexto y las modalidades mediante la cuales el Examen debió de divulgarse. En efecto, nos encontramos ante una tradición sumamente activa, puesto que las copias de la apología se difundieron y realizaron en un ambiente culturalmente dinámico y gracias a la labor, por lo general muy atenta, de amanuenses y lectores que iban manejando distintas obras de la polémica, que conocían de memoria fragmentos enteros del poema de Góngora (o, en cualquier caso, podían compulsar en todo momento sus copias de las Soledades), y que eran, en ocasiones, lo bastante eruditos como para intervenir con enmiendas e interpolaciones. En consecuencia, se nos antoja poco prudente excluir la posibilidad de que tanto las modernizaciones o correcciones de los versos citados de las Soledades como la interpolación de "predicador de Su Majestad" se remonten a la mano de un copista experto y atinado, o incluso de un curioso lector. A fin de cuentas, no se trataría de ninguna excepción, ya que intervenciones análogas caracterizan a otros testimonios: por ejemplo, en $\delta$ la modernización del verso «en

58 «Paravicino debía de ser ya predicador muy famoso, cuando en diciembre de 1617 Felipe III le concedió el título de Predicador Real, poco después de que Góngora obtuviese la Capellanía de honor» (Cerdan 1978: 46). 
dehesas azules pace estrellas» con la lección «en campos de zafiro pace estrellas»; o en M2 la interpolación de la glosa marginal "Luis Tribaldos de Toledo chronista de Su Majestad / don Iñigo Aguirre caballero del hábito de Santiago" que acompaña al elenco de defensores de Góngora trazado por Fernández de Córdoba.

La combinación de estos factores, ignorados por López Viñuela -la plausible existencia de $\Omega$ y el carácter tan activo de esta tradición-, junto con la aparente "incongruencia" del manuscrito A - dicho testimonio, plagado de corruptelas banales, normalmente es el más fiel y correcto en las citas tanto de autoridades clásicas e italianas como del poema gongorino, y además deja espacios en blanco por la probable dificultad de lectura que oponía su modelo-, nos llevan a suponer al menos un interpositus $\varepsilon$ entre el mismo A y el arquetipo. Sería, por tanto, en $\varepsilon$ donde un copista, o un lector erudito, habría subsanado o modernizado ope ingenii las citas gongorinas.

El stemma codicum que sintetiza todos los pasajes de nuestra reconstrucción genealógica es el siguiente:

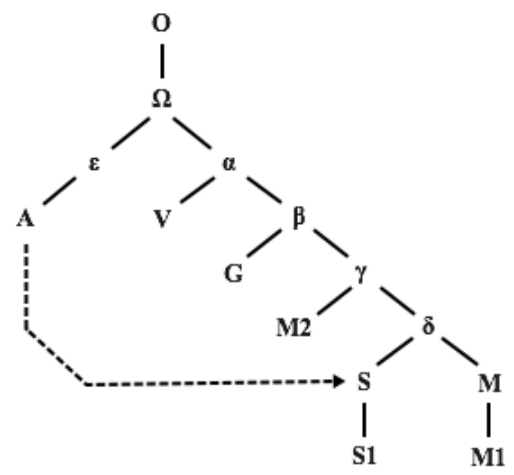




\section{BIBLIOGRAFÍA CITADA}

Alonso, Dámaso (1975). «Góngora en las cartas del Abad de Rute». En Homenaje a la memoria de D. Antonio Rodríguez Moñino 1910-1970. Madrid: Castalia, pp. 27-58.

Artigas Ferrando, Miguel (1925). Don Luis de Góngora y Argote. Biografia y estudio crítico. Madrid: Real Academia Española.

Asor Rosa, Alberto (dir.) (1991). Letteratura italiana. Gli autori. Dizionario bio-bliografico e Indice, vol. II. Torino: Einaudi.

Blecua, Alberto (2012). Estudios de crítica textual. Madrid: Gredos.

- (2001). Manual de crítica textual. Madrid: Castalia.

BRANDOLI, Caterina (2007). «Due canoni a confronto: i luoghi di Barbi e lo scrutinio di Petrocchi». En Paolo Trovato (ed.), Nuove prospettive sulla tradizione della Commedia. Una guida filologico linguistica al poema dantesco. Firenze: Cesati, pp. 99-214.

CERDAn, Francis (1978). «Elementos para la biografía de fray Hortensio Félix Paravicino y Arteaga». Criticón, 4, pp. 39-74.

Darst, David H. (1985). Imitatio. (Polémicas sobre la imitación en el Siglo de Oro). Madrid: Orígenes.

Elvira, Muriel (2015). Parecer de don Francisco de Córdoba acerca de las Soledades a instancia de su autor. Université Paris-Sorbonne: LABEX OBVIL. Disponible online: http://obvil.paris-sorbonne.fr/corpus/gongora/1614_parecer/.

EsPINOSA, Pedro (2010). El perro y la calentura. Novela peregrina. Alicante: Biblioteca Virtual Miguel de Cervantes. Disponible online: http:/www.cervantesvirtual.com/nd/ ark:/59851/bmcst 858 .

Fernández de CóRdobA, Francisco. Parecer de don Francisco de Córdoba acerca de las Soledades a instancia de su autor. En BFBM, ms. 18/10/11: Contra la pestilente poesía, ff. $131 \mathrm{r}-145 \mathrm{v}$.

GóngORA Y ARGOTE, Luis de (1994). Soledades. Robert Jammes (ed.). Madrid: Castalia.

Herrera, Fernando de (1985). Poesía castellana original completa. Cristóbal Cuevas (ed.). Madrid: Cátedra.

Horacio, Quinto Flaco (1985). Opera. David Roy Shackelton Bailey (ed.). Stuttgart: Teubner. (1984). Opera. Stephanus Borzsák (ed.). Leipzig: Teubner.

JAMmES, Robert (1962). «L'Antidote de Jáuregui annoté par les amis de Góngora». Bulletin Hispanique, 64, 3-4, pp. 193-215.

JÁuregui, Juan de (2002). Antídoto contra la pestilente poesía de las Soledades por Juan de Jáuregui. José Manuel Rico García (ed.). Universidad de Sevilla: Secretariado de Publicaciones.

Lilao Franca, Óscar, y Castrillo GonzÁlez, Carmen (dirs.) (2002). Catálogo de manuscritos de la Biblioteca Universitaria de Salamanca, II, Manuscritos 1680-2777. Universidad de Salamanca: Ediciones Universidad de Salamanca.

LóPEz BuEno, Begoña (2000). La poética cultista de Herrera a Góngora. Sevilla: Alfar.

LÓPEZ VIÑUELA, Ana Cristina (1998). «El tratamiento de las citas en la edición crítica del Examen del Antídoto, del abad de Rute». En Antonio Chas Aguión et al. (eds.), Edición y anotación de textos. Actas del Primer Congreso de Jóvenes Filólogos, vol. 2. Universidade da Coruña: Servicio de Publicaciones, pp. 377-388. 
MAAs, Paul (2012). Crítica del texto. Andrea Baldissera y Rafael Bonilla Cerezo (trads.). Sevilla: Universidad Internacional de Andalucía.

Montanari, Elio (2003). La critica del testo secondo Paul Maas: testo e commento. Firenze: SISMEL Edizioni del Galluzzo.

Montero Delgado, Juan (2014). «Francisco Pacheco editor de obras de Fernando de Herrera: análisis de un documento inédito». Bulletin of Spanish Studies, 91-2, pp. 2-14.

Orozco DíAz, Emilio (1973). Lope y Góngora frente a frente. Madrid: Gredos.

QuAGLIONI, Diego (2007-2008). «Dal costituzionalismo medievale al costituzionalismo moderno». Annali del seminario giuridico, 52, pp. 55-67.

Roses Lozano, Joaquín (2007). Góngora: "Soledades" habitadas. Málaga: Servicio de Publicaciones de la Universidad de Málaga.

(1994). Una poética de la oscuridad. La recepción crítica de las "Soledades" en el siglo XVII. Madrid: Tamesis.

Salcedo Coronel, José García de (1644). Segundo tomo de las obras de don Luis de Góngora comentadas por don García de Salcedo Coronel. Madrid: Diego Díaz de la Carrera.

SEgRe, Cesare (2016). «Apuntes sobre el problema de las contaminaciones en los textos en prosa». Creneida, 4, pp. 8-13.

SINE NOTIS (1984). Inventario general de Manuscritos de la Biblioteca Nacional, X, (3027 a 5699). Madrid: Ministerio de Cultura (Dirección General del Libro y Bibliotecas).

SinE NOTIS (1581). Suidae Historicae caeteraque omnia quae ulla ex parte ad cognitionem rerum spectant. Basileae: ex officina Hervagina per Eusebium Episcopum.

Storey, Ian C. (2003). Eupolis. Poet of Old Comedy. Oxford: Oxford University Press.

STussi, Alfredo (1994). Introduzione agli studi di filologia italiana. Bologna: Il Mulino.

TANGANelli, Paolo (2016). «Fenómenos de contaminación en la Llama de amor viva (tradición $A$ ) de San Juan de la Cruz». Creneida, 4, pp. 177-238.

Trovato, Paolo (2014). Everything you always wanted to know about Lachmann's Method. Padova: libreriauniversitaria.it.

- (2005). «Archetipo, stemma codicum e albero reale». Filologia Italiana, 2, pp. 1-18.

VÀrvaro, Alberto (2006). «Critica dei testi classica e romanza». En Alberto Stussi (ed.), Fondamenti di critica testuale. Bologna: Il Mulino, pp. 85-100.

Virgilio, Publio Marón (2009). Aeneis. Gian Biagio Conte (ed.). Berlin: Gruyter. (1992). Eneida. Vicente Cristóbal (ed.) y Javier de Echave-Sustaeta (trad.). Madrid: Gredos.

Recibido: $15 / 7 / 2017$

Aceptado: 3/11/2017

Edad de Oro, XXXVI (2017), pp. 191-232, ISSN: 0212-0429 


\title{
tox \\ HaCIA UNA EDICIÓN CRÍTICA DEL EXAMEN DEL ANTÍDOTO de Francisco Fernández de Córdoba
}

RESUMEN: El presente trabajo analiza la tradición textual del Examen del Antídoto de Francisco Fernández de Córdoba, abad de Rute. En particular, el ensayo se divide en dos partes: en la primera, se ofrece la descripción física de los testimonios conservados y cotejados; en la segunda, se examinan los errores localizados con el objeto de presentar las varias familias y sus relaciones. Se concluye con la propuesta de una hipótesis estemática. Palabras clave: Francisco Fernández de Córdoba, Examen del Antídoto, polémica gongorina, método neolachmanniano, stemma codicum.

\section{TOWARS A CRITICAL EDITION OF FRANCISCO FERNÁNDEZ DE CÓRDOBA'S EXAMEN DEL ANTÍDOTO}

\begin{abstract}
This article analizes the textual tradition of Francisco Fernández de Córdoba's Examen del Antídoto. Particularly, the essay is divided into two parts: in the first one, we provide a physical description of the collected and collated witnesses; in the second one, we examine the detected errors with the aim of presenting the existing families and their relations. We conclude with the proposal of a stemmatic hypothesis.
\end{abstract}

Keywords: Francisco Fernández de Córdoba, Examen del Antídoto, Gongorine polemic, Lachmann's method, stemma codicum. 


\section{EDAD DE ORO}

Revista de Filología Hispánica XXXVI

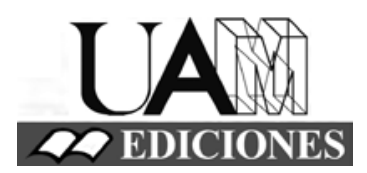




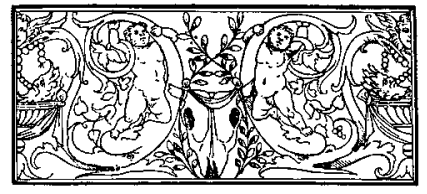

\section{Edad de Oro. Revista de Filología Hispánica}

ISSN: 0212-0429

Dirección:

Teodosio Fernández

Secretaría y edición:

José Ramón Trujillo

Consejo de redacción:

Manuel Piqueras

Blanca Santos

Admisión de originales:

María Jesús Zamora

Edad de Oro

Departamento de Filología Española

Universidad Autónoma de Madrid

28049 Madrid (España)

Tfno.: +0034914974090

correo: mariajesus.zamora@uam.es

Distribución, suscripción y venta:

Servicio de Publicaciones de la UAM

Universidad Autónoma de Madrid

28049 Madrid (España)

Intercambio de publicaciones:

Biblioteca de la Facultad de Filosofía y

Letras (UAM)

Universidad Autónoma de Madrid

28049 Madrid (España)
Comité científico internacional:

Carlos Alvar (Univ. de Ginebra)

Ignacio Arellano (Univ. de Navarra)

Javier Blasco (Univ. de Valladolid)

Alberto Blecua (UAB)

Jean Canavaggio (Univ. de París X)

Laura Dolfi (Univ. de Turín)

Aurora Egido (Univ. de Zaragoza)

Víctor García de la Concha (RAE)

Luciano García Lorenzo (CSIC)

Joaquín González Cuenca (Univ. de

Castilla-La Mancha)

Agustín de La Granja (Univ. de Granada)

Begoña López Bueno (Univ. de Sevilla)

Michel Moner (Univ. de Toulouse III)

Joan Oleza (Univ. de Valencia)

Alfonso Rey (Univ. de Santiago)

Lina Rodríguez Cacho (Univ. de Salamanca)

Leonardo Romero Tobar (Univ. de Zaragoza)

Aldo Ruffinatto (Univ. de Turín)

Lía Schwartz (City University of New York)

Han colaborado en este volumen:

Departamento de Filología Española (UAM)

Facultad de Filosofía y Letras (UAM)

Edad de Oro se recoge, entre otras, en las siguientes bases de datos: SCOPUS, MLA Database, HLAS, Latindex, PIO-Periodical Content Index, ISOC, Dialnet, MIAR, ERIH Plus, DICE, Sumaris CBUC, Ulrich's. Se encuentra evaluada en CIRC: A; MIAR difusión ICDS live 2016: 10.0; INRECH; SCImago Journal \& Country Rank: H Index 3, SJR SCImago Journal \& Country Rank 0,1, Q4; RESH índice de impacto: 0.041; ERIH: A INT1; Carhus Plus+2014: C. 